\title{
Objectivity in Legal Judgment
}

Heidi Li Feldman

Georgetown University Law Center, feldmanh@georgetown.edu

This paper can be downloaded free of charge from:

https://scholarship.law.georgetown.edu/facpub/1715

92 Mich. L. Rev. 1187

This open-access article is brought to you by the Georgetown Law Library. Posted with permission of the author. Follow this and additional works at: https://scholarship.law.georgetown.edu/facpub

Part of the Legal Profession Commons 


\title{
OBJECTIVITY IN LEGAL JUDGMENT
}

\author{
Heidi Li Feldman*
}

\section{INTRODUCTION}

We are experiencing a crisis of confidence in the idea of objectivity. In scholarly circles, many are ready to discontinue talk of objectivity altogether, on the grounds that it has been nothing more than a mask for the oppressive practices of politically and economically privileged groups, promising neutrality where in fact there are only power relations. Some feminist legal scholars, some critical race scholars, and some critical legal studies scholars, along with some contemporary philosophers, argue that objectivity is inevitably a problematic, dangerous idea or ideal. Critics of objectivity sometimes argue that it can never be genuinely had, only claimed under false pretenses and then used oppressively. ${ }^{1}$

On the strongest reading of their ideas, critics of objectivity insist that we entirely eliminate the idea of objectivity from our conceptual vocabulary. Different commentators base their insistence on different grounds. Feminist critics reject objectivity because, in their view, it is inextricably connected to male power and female subordination; purging objectivity from our conceptual vocabulary is prerequisite to the elimination of these evils. ${ }^{2}$ Some philosophers claim that objectivity is, at best, chimerical, and that, at worst, it limits our capacity to imagine and create new and better moral and political lives for ourselves. According to these critics, abandoning objectivity would save us from

* Assistant Professor of Law, University of Michigan. B.A. 1986, Brown; J.D. 1990, Ph.D. (Philosophy) 1993, Michigan.-Ed. I would like to express my warmest, deepest thanks to the many colleagues in the University of Michigan Law School and Department of Philosophy who read drafts of this work for their generosity in commenting upon and discussing it throughout the stages of its development.

1. Commentators critical of objectivity include the feminist legal scholar Catharine MacKinnon, the critical race scholar Richard Delgado, and the philosopher Richard Rorty. See Catharine A. Mackinnon, Toward a Feminist Theory of the State 120-24 (1989); RICHARD RORTY, Solidarity or Objectivity, in OBJECTIVITY, RELATIVISM, AND TRUTH 21 (1991); Richard Delgado, The Inward Turn in Outsider Jurisprudence, 34 WM. \& MARY L. REV. 741, 762-68 (1993). For a composite overview of feminist objections to objectivity, see SANDRA HARDING, WhOSE SCIENCE? WhOSE KNOWLEDGE?: THINKING FROM WOMEN'S LIVES 15759 (1991). Objectivity is controversial in fields other than law and philosophy. For a discussion of critics of objectivity as a journalistic ideal and a rebuttal of these criticisms, see Judith Lichtenberg, In Defense of Objectivity, in MASS MEDIA AND SOcIETY 216 (James Curran \& Michael Gurevitch eds., 1991).

2. See, e.g., MACKINNON, supra note 1, at 120-25. 
both epistemological and ethical error. ${ }^{3}$

Other critics of objectivity condemn it less strenuously. They regard the idea of objectivity as dispensable, if not dangerous. According to some such critics, talk of objectivity tends to inhibit our thinking, curtailing arguments that ought to continue. ${ }^{4}$ According to others, talk of objectivity makes us feel more constrained than we really are. ${ }^{5}$ In either case, the idea of objectivity offers little in the way of positive power, according to these critics, and so relinquishing it imposes little cost.

Skepticism and cynicism about objectivity, especially objectivity in law, is not restricted to scholars. We find it among the general public, surfacing in reaction to controversial trial judgments, such as those reached in the Rodney King and Reginald Denny beatings trials, and in response to Supreme Court judgments on sensitive matters, such as abortion and voting rights. Contentious legal judgments invite doubt about the law's capacity for objectivity.

I take seriously concerns about the potential dangers of the idea or the ideal of objectivity and worries about whether objectivity is illusory. But objectivity is a very powerful idea, one that we could, perhaps, put to good use in criticizing what merits criticism and praising what merits praise. Before we abandon the idea or ideal of objectivity altogether, we should see whether we can elucidate it in a way that answers to that which seems worthwhile in the concept without including that which seems pernicious. This elucidation will enable us to gain a clear picture of the costs and benefits of retaining the idea and the ideal. Then, but only then, we will be ready to consider when, if ever, objectivity is a concept worth keeping in currency.

Popular understanding of science has given us one very simple conception of objectivity. According to this rather vague, prereflective conception, objectivity is a matter of correspondence to the world as it "really" is, independent of our practices, goals, values, and beliefs. Objective judgments track this human-independent world. For those seeking objectivity in legal judgment, a problem emerges immediately upon consideration of this simple conception. The phenomena identified by legal concepts such as negligence, fraud, and rape are not like the phenomena identified by natural scientific concepts like proton or

3. See, e.g., RORTY, supra note 1, at 27-28, 33-34.

4. See, e.g., RONALD DWORKIN, LAW's EMPIRE 80-83 (1986) [hereinafter DWORKIN, EMPIRE]; Ronald DWORKIN, A MatTer of PRINCIPLe 171-74 (1985) [hereinafter Dworkin, PRINCIPLE].

5. See, e.g., Duncan Kennedy, Freedom and Constraint in Adjudication: A Critical Phenomenology, 36 J. LeGAL Educ. 518, 520-21 (1986). 
gravity. Negligence, fraud, and rape are not human-independent phenomena; they are constituted by our practices, goals, values, and beliefs. Legal judgments that apply concepts like negligence, fraud, and rape are not purely descriptive. ${ }^{6}$ These legal judgments do not aspire to correspond to a human-independent world, free from our practices, goals, values, and beliefs. If we have only the simple correspondence conception of objectivity available to us, it would seem that we have to surrender the possibility of objectivity in legal judgment. Many legal judgments do not fit into this conception of objectivity at all. ${ }^{7}$

Nor would most legal judgments fit into a conception of objectivity suitable for wholly evaluative or purely normative judgments, judgments that apply concepts with little or no descriptive content. An example of a more purely evaluative concept is good; an example of a more purely normative concept is ought. These concepts apply appropriately under an extremely wide variety of factual circumstance, serving as all-purpose evaluative or prescriptive devices. Even though fraud and negligence have a negative evaluative flavor or component, it would be extremely odd to call torture fraud or negligence, whereas it would not be odd to call it bad. This is true because it will practically always be inappropriate, due to the descriptive dimensions of fraud and negligence, to apply these concepts to torture, even though it is practically always appropriate to evaluate torture negatively. Moreover, fraud and negligence do not negatively evaluate torture in an apt way. Due to the intricate interweaving of the descriptive and the evaluative dimensions of these concepts, they evaluate in distinctive and particular ways. ${ }^{8} \mathrm{Bad}$, on the other hand, aptly negatively evaluates circumstances ranging from torture to spitting on a public bus. That is because its evaluative dimension is more general and less nuanced than the evaluative dimensions of negligence or fraud.

We do not have a straightforward prereflective conception of objectivity for more purely evaluative and more purely normative judgments, as we do in the case of more purely descriptive judgments. But, because more purely evaluative and more purely normative judgments are less closely world-guided than the kinds of legal judgments I have been noting, it is prima facie unlikely that a conception of objectivity suitable for more purely evaluative or normative judgments would be

6. Throughout this essay, I speak of "applying" concepts. Note that both the use and the nonuse of a concept count as "applications" - that is, a decision not to use a concept is as much an instance of applying it as is a decision to use it.

7. Whether even scientific judgments fit into this conception is a separate question, which I pursue briefly in Part II of this essay. See infra text accompanying notes 49-53.

8. I clarify and pursue the nature of the connection between the descriptive and evaluative in concepts like fraud and negligence in Part I. See infra text accompanying notes 14-41. 
suitable for more closely world-guided judgments, including the legal judgments mentioned so far. ${ }^{9}$

The situation confronting the defender of the idea or ideal of objectivity in legal judgment worsens. If neither the correspondence conception of objectivity nor a conception of objectivity suitable for purely evaluative or purely normative judgments is suitable for many legal judgments, what avenues remain along which to develop a suitable conception of objectivity for them?

I propose that we start by getting a better grip on the nature of the concepts that figure in so many legal judgments: concepts that seem to blend description and evaluation, which I will henceforth refer to as blend concepts. Not all blend concepts are legal concepts - consider loyalty, rude, funny, or brutality. ${ }^{10}$ If we could develop a conception of objectivity suitable for blend judgments - that is, judgments that apply blend concepts - we would arrive at a conception of objectivity suitable for many legal judgments: all those that apply blend legal concepts.

Twentieth century moral philosophers have devoted much energy and space to considering blend concepts. ${ }^{11}$ Legal concepts do not figure in these discussions, despite the fact that legal scholars have noticed that many of these concepts exhibit the traits that drew philosophers' attention in the first place. ${ }^{12}$ Neither philosophers nor

9. I pursue and defend this claim in Part II, where I consider carefully conceptions of objectivity in moral and political judgment developed by, respectively, Jürgen Habermas and John Rawls. See infra text accompanying notes 49-71.

10. Whether all distinctively legal concepts are blend concepts is a harder question, but one that we can set aside for now.

11. Bernard Williams's and David Wiggins's works particularly inform my subsequent discussion in this essay. See generally David Wiggins, A Sensible Subjectivism?, in NeEds, VAlues, Truth 185 (1987); Bernard Williams, Ethics aND the Limits of Philosophy (1985). Elizabeth Anderson, Simon Blackburn, Allan Gibbard, John McDowell, and Charles Taylor have also discussed issues relating to blend concepts. See ElizabeTH ANDERSON, Value in EThics aNd Economics 91-116 (1993); Simon Blackburn, Spreading the Word 148-63 (1984); Simon Blackburn, Through Thick and Thin, 66 Proc. ARISTOTELIAN Socy. 285 (Supp. 1992); Allan GibBard, Wise ChOICES, APT Feelings 112-25 (1990); Allan Gibbard, Thick Concepts and Warrant for Feelings, 66 Proc. ARISTOTELIAN SocY. 267 (Supp. 1992); John McDowell, Projection and TruTh IN Ethics (1988); John McDowell, Ethics and the Limits of Philosophy, 95 Mind 377 (1986) (book review) [hereinafter McDowell, Ethics]; John McDowell, Values and Secondary Qualities, in MORALITY AND OBJECTIVITY 110 (Ted Honderich ed., 1985) [hereinafter McDowell, Values]; CharLes TAYLoR, Interpretation and the Sciences of Man, in 2 Philosophical PAPERS 15 (1985) [hereinafter TAYLOR, Interpretation]; Charles TAylor, What Is Human Agency?, in 1 Philosophical Papers 15 (1985). Philippa Foot and R.M. Hare have debated the proper philosophical analysis of concepts with some of the traits that belong to blend concepts. See PhILIPPA Foot, Moral Arguments, in VIRTUES AND Vices 96 (1978) [hereinafter Foot, Moral Arguments]; PHILIPPA FoOT, Moral Beliefs, in VIRTUES AND VICES, supra, at 110; R.M. HARE, Descriptivism, in EsSAYS ON THE MORAL CoNCEPTS 55 (1972).

12. See Dworkin, Principle, supra note 4, at 119-27; A.W.B. Simpson, The Analysis of Legal Concepts, in Legal Theory aND Legal History 335 (1987); H.L.A. Hart, Definition 
legal scholars have carefully delineated the distinctive characteristics of blend concepts. Philosophers have not seriously or extensively addressed the question of whether such concepts are capable of objective application. ${ }^{13}$ In legal scholarship, on the other hand, objectivity has been a major preoccupation, but the debates have not focused on the application of blend legal concepts.

This essay unites the philosophical concern with blend concepts and the legal concern with objectivity. Comparing blend legal concepts with other kinds of blend concepts develops our resources for ascertaining the distinctive characteristics of blend concepts. Cultivating a more refined understanding of blend concepts sharpens our inquiry into objectivity. In Part I of this essay, I explicate the distinctive characteristics of blend concepts, demonstrating that some representative legal concepts, drawn from tort law, possess these characteristics. In Part II, I develop a conception of objectivity suitable for blend judgments - the blend conception of objectivity - and use this conception to evaluate some representative blend legal judgments, including judgments of negligence, judgments of what is speech, and judgments of rape. Finally, in Part III, I situate my discussion of the objectivity of blend judgments in the context of legal scholarship regarding objectivity, using the blend conception of objectivity to diagnose some hidden problems in previous discussions of objectivity in law.

\section{UNDERSTANDING BLEND CONCEPTS}

\section{A. Distinguishing Blend Concepts}

When discussing issues raised by blend concepts, philosophers

and Theory in Jurisprudence, 70 LAw Q. REV. 37 (1954). Felix Cohen noticed blend concepts only to lavish skepticism upon them:

In every field of law we should find peculiar concepts which are not defined either in terms of empirical fact or in terms of ethics but which are used to answer empirical and ethical questions alike, and thus bar the way to intelligent investigation of social fact and social policy. Corporate entity, property rights, fair value and due process are such concepts. So too are title, contract, conspiracy, malice, proximate cause, and all the rest of the magic "solving words" of traditional jurisprudence.

Felix S. Cohen, Transcendental Nonsense and the Functional Approach, 35 CoLUM. L. REV. 809, 820 (1935). My discussion of blend concepts opposes this sort of skepticism, as will become apparent in the subsequent text. Cohen's remarks suggest a prescriptivist approach to such concepts. For an explanation and critical evaluation of this approach, see infra note 36.

13. Some philosophers have presented preliminary discussions of objectivity in application of ethical blend concepts, but these discussions have been impeded, in my view, by the absence of a careful delineation of blend concepts. See, e.g., Hilary PUTNam, Objectivity and the Science/ Ethics Distinction, in REALISM WITH A HUMAN FACE 163, 163-78 (1990); WIGGINS, supra note 11; Williams, supra note 11, at 132-55; McDowell, Ethics, supra note 11; Warren Quinn, Reflections on the Loss of Moral Knowledge: Williams on Objectivity, 16 PHIL. \& PUB. AFF. 195 (1987) (book review). 
have considered concepts such as rude, courage, and gratitude. 14 Legal scholars have explored blend concepts such as crime, ownership, and State. ${ }^{15}$ In both philosophical and legal scholarship, commentators proffer these concepts as categorically different from concepts that do not blend description and evaluation, such as red, water, or proton. ${ }^{16}$ Yet it can be difficult to formulate a principled, illuminating delineation that will include the former but exclude the latter.

Philosophers' and legal scholars' efforts in this direction tend to be overinclusive, underinclusive, or both. Bernard Williams, for instance, discusses "thick concepts"; he considers a concept "thick" if its application is "world-guided" and "action-guiding" by virtue of the way in which it is world-guided. ${ }^{17}$ This designation picks out too many concepts: all those whose application is guided by how the world is and thereby tend to guide action. Concepts like water and proton would seem to qualify. The application of water depends on the state of the world, and identifying that state of the world (by applying water) regularly guides people to drink; the application of proton depends on how the world is and at minimum guides the actions of those physicists applying the concept in the first place. Yet water and proton are supposed to be categorically different from rude or negligent.

At the same time, Williams's delineation includes too few concepts. Williams focuses on action as the upshot of application. But consider, for example, negligence. A judgment that somebody's conduct has been negligent does not lead to action in any straightforward way. Even if we grant that finding liability counts as an action, judg-

14. Contemporary moral philosophers have, in the main, attended to blend concepts either to motivate or test their positions on epistemological, metaphysical, and semantic issues in the debate over value realism. My own inquiry into blend concepts focuses firmly on epistemology, specifically on the epistemological issue of whether these concepts can be applied objectively. Turning to these questions allows me to deemphasize matters such as how best to analyze the content of blend concepts or the nature of their ontological status. This means that officially I am agnostic when it comes to the dispute over whether the content of a blend concept is factstating, whether a blend concept merely expresses the speaker's attitudes or acceptance of a certain system of norms, or whether its content combines fact and value in a categorical way.

15. Crime is one of the concepts Dworkin mentions when he discusses "dispositive concepts." DWORKIN, PRINCIPLE, supra note 4, at 119; see infra text accompanying note 23 . Brian Simpson uses ownership as one example in his discussion of legal concepts that, when applied, dictate certain results. SiMPSON, supra note 12, at 353. Simpson notes that these concepts have several other distinctive traits. His list overlaps those that distinguish blend concepts from others. See infra text accompanying notes 27-41. State is one of Hart's examples in his identification and analysis of legal concepts that "do not have the straightforward connection with counterparts in the world of fact which most ordinary words have" - that is, legal concepts that are not purely descriptive. Hart, supra note 12, at 37-38. For a discussion of my rejection of Hart's analysis of these concepts, see infra note 36.

16. See, e.g., Foot, Moral Arguments, supra note 11, at 101-06; HART, supra note 12, at 38 39; SiMPSON, supra note 12, at 347-58; WILLIAMS, supra note 11, at 129, 140-41.

17. Williams, supra note 11 , at $129-30,140-41$. 
ing conduct negligent does not even lead directly to such a finding; even when it does, the connection between that judgment and action can be tenuous. The defendant may refuse to pay damages, the plaintiff may not try to enforce the judgment, and others might not be deterred from acting the way the defendant had acted. A judgment of negligence is as compatible with inaction as with action, even if such judgments often do provoke action. ${ }^{18}$

Another contemporary philosopher, David Wiggins, discusses "anthropocentric concepts." 19 He identifies these as concepts that refer to a property that cannot be characterized illuminatingly without reference to subjective responses that, in turn, cannot be characterized illuminatingly without reference to the property denoted by the concept. ${ }^{20}$ One of Wiggins's usual examples is the concept funny, which, he maintains, cannot be elucidated without reference to the characteristic subjective response of amusement that, in turn, cannot be elucidated without reference to what it is to be funny. ${ }^{21}$ While Wiggins's delineation at least arguably rules out proton, it certainly does not rule out a concept like red or a psychological concept like schizophrenic. Both of these seem - at least as much as does Wiggins's usual example of funny - to refer to properties that cannot be characterized illuminatingly without reference to subjective responses that, in turn, cannot be characterized illuminatingly without reference to the property denoted by the concept. ${ }^{22}$ Now, we might rest easy with a delineation of blend concepts that included schizophrenic in the class - because one can plausibly argue that schizophrenic blends description and evaluation - but it seems pretty clear that we want a delineation that excludes red.

Like a delineation of blend concepts modeled on thick concepts, a delineation modeled on anthropocentric concepts is underinclusive as well as overinclusive. Wiggins's quintessential anthropocentric concept, funny, belongs to the < property-response > pair < funninessamusement $>$. Grant that funniness cannot be characterized illuminatingly without reference to amusement and vice versa. Never-

18. In articulating her own characterization of blend concepts, Elizabeth Anderson points out a variety of circumstances under which one might sincerely conclude that a blend concept applies but fail to experience any corresponding motivational tug. ANDERSON, supra note 11, at 102-03.

19. WIGGINS, supra note 11 , at 194-99.

20. Id. at 195.

21. Id.

22. McDowell explicitly recognizes this problem and acknowledges the distinction between concepts whose parameters are defined in part by "normal" responses and concepts whose parameters are defined in part by appropriate responses or responses one should have. McDowell, Values, supra note 11 , at 118. 
theless, not every concept that blends description and evaluation is a member of such a pair. Negligence, like other blend legal concepts, is not illuminatingly characterized with reference to a subjective, sentimental response on a par with amusement.

Ronald Dworkin identifies "dispositive concepts" as legal concepts with the following characteristic: "If the concept holds in a particular situation, then judges have a duty, at least prima facie, to decide some legal claim one way; but if the concept does not hold, then judges have a duty, at least prima facie, to decide the same claim in the opposite way." ${ }^{23}$ His examples are valid contract, civil liability, and crime. Each of these "dispositive concepts" are blend concepts. They combine description and evaluation, simultaneously identifying a state of affairs and evaluating it, thereby guiding a judge's decision. ${ }^{24}$ As I will argue below, ${ }^{25}$ all blend concepts provide reasons for action, belief, or feeling. Thus, the applicability of valid contract, civil liability, or crime provides a reason for a judge to decide in a particular way. It may be that in these instances the reason exists in the form of a duty - it is plausible to think that having a duty to act in a certain way is a reason to do so - but not all blend concepts impose duties, even if they provide reasons. Consider funny. That a movie is funny might well provide a reason to see it or a reason to laugh at it, but that a film is funny does not impose a duty to do either of these things. If Dworkin is correct that blend legal concepts, when applied, impose duties, then he has perhaps delineated a subset of blend concepts, whose members are reason-giving by virtue of being duty-imposing. But he has not provided the delineation we are seeking.

To establish the blend concept category, we need a delineation that excludes red, chair, and proton and includes rude, funny, and negligence. ${ }^{26}$ We know that concepts such as negligence appear to blend description and evaluation and tend to guide action, belief, and feeling. Now we need to elucidate these traits further and see whether additional traits distinguish blend concepts from other kinds.

\section{B. The Traits of Blend Concepts}

A quick characterization of blend concepts: they apply only under

23. Dworkin, Principle, supra note 4, at 119.

24. The nature and origins of duties are complex matters: whether or not the guidance results from a duty imposed by the applicability of these concepts is a question I will set aside here.

25. See infra text accompanying notes 32-33.

26. The status of schizophrenic is more complicated. Whether and how it falls into the blendconcept category are matters to which I return after developing a fuller account of the traits of blend-concepts. See infra text accompanying notes 40-41. 
certain factual circumstances and, at the same time, they evaluate those circumstances; when they do apply, they tend to guide our actions, beliefs, and feelings. This characterization raises more questions than it answers. What is the connection between the descriptive and evaluative aspects of a blend concept, particularly as the blend relates to its applicability in specific situations?. Why do blend judgments tend to guide our actions, beliefs, and feelings? A delineation of the traits of blend concepts should answer these questions. In this section, I provide one.

Blend concepts are members of evaluative taxonomies. Evaluative taxonomies categorize the world for us, just as scientific taxonomies do, but they afford us evaluative, rather than explanatory, power. They enable us to make distinctions of worth rather than distinctions of causal role. By taxonomizing worth, evaluative taxonomies create standards for making discriminations that enable us to respond to a wide array of complex human needs and interests. In turn, the ability to make certain discriminations entrenches - and sometimes generates - particular needs and interests.

$R$ ude belongs to the evaluative taxonomy of etiquette. Other blend concepts of etiquette, such as polite, gracious, and vulgar, mark additional categories in this taxonomy. Funny belongs to the evaluative taxonomy of humor. Other members include facetious, waggish, and slapstick. Negligence belongs to the evaluative taxonomy of tort law, as do reasonable person under like circumstances, and unreasonable risk. In each of these instances, categories of the specific evaluative taxonomy comprise a set of complex standards that we use to navigate the domains of etiquette, humor, and tort law. These concepts influence our attitudes and our behavior, affecting our actions and our reactions to the actions of others.

Correct application of the concepts comprising an evaluative taxonomy turns, in part, on whether certain facts, marked out by the taxonomy, obtain. ${ }^{27}$ Most often, but not always, these facts will be social, not natural - that is, the facts that guide the application of the concept will have to do with things like conventional mores, shared cultural ideas, community values, and customs. But correct application of a blend concept, particularly in unforeseen and controversial cases, also turns on successfully ascertaining and interpreting the evaluative point(s) of the relevant taxonomy. A taxonomy's evaluative point - it may have more than one, but, for the sake of convenience, I

27. When I speak of correctly, properly, or appropriately applying blend concepts, I mean applying them in ways that experienced users would find acceptable or appropriate based on their familiarity with prevailing norms of use. 
will use the singular here - derives from the functions of the taxonomy. Evaluative taxonomies are responsive to particular human needs and interests. A taxonomy's evaluative point depends upon what it takes to satisfy these needs and interests. Correctly applying a blend concept requires sensitivity to the underlying human needs and interests addressed by the evaluative taxonomy to which the concept belongs and to the evaluative point the taxonomy has by virtue of the way it responds to these needs and interests. In run-of-the-mill applications of a blend concept, all this remains tacit.

Sometimes, however, in the course of applying a blend concept, one confronts situations in which the facts cut both for and against application. In these situations, one must consciously decide whether to apply the concept. Further facts will not settle the matter. Instead, one must consult the evaluative point that informs the concept in question to decide whether this point would be better served by applying the concept or refusing to do so. This can be a complicated task, any conclusion of which is likely to be contestable. Consider, for example, the matter of how to treat telephone solicitations. You are trying to prepare dinner or get ready for work when the telephone rings. The person on the other end of the line asks for you by name, and, when you acknowledge your identity, he launches into the inexorable patter of a sales pitch. You want to interrupt him, to tell him you are not interested in whatever he is pitching, regardless of what it is, but you are held back by the powerful intuition that to do so would be rude. After the call, you realize you had better decide if the course of action you refrained from is in fact rude, so that next time you will be prepared to act on the impulse to cut off the salesperson, if indeed it would not be rude to do so.

Here are some initial considerations relevant to your deliberations: Ordinarily, it is rude to interrupt people in the midst of their remarks, particularly when they are speaking in a way that indicates that they do not want to be interrupted. Interruption is least rude - perhaps not at all rude - when the conversation is casual; friends have more license than others in this respect. Delivering his seamless patter, the salesperson at the other end of the line makes it quite clear that he does not want to be interrupted. He is no friend of yours, either: he is a stranger, calling on business. In these respects, this situation seems like one in which interruption would be rude. But there are further considerations. There are circumstances in which interruption is appropriate among those who are not friends: it can be appropriate for a superior to interrupt somebody she supervises; it can be appropriate for a person angry with another to interrupt; it can be appropriate for 
anyone to interrupt a speaker when there is an emergency of which the speaker is not aware. Insofar as the salesperson is one who ought to defer to a customer, insofar as his call has angered you, insofar as you are in the midst of activities of which he is not aware, the telephone solicitation situation resembles ones in which it is permissible to interrupt.

Different aspects of the situation weigh for and against deeming the proposed course of conduct rude. To settle the issue, you need to consult the evaluative point(s) of etiquette. To identify these, you need to think about the needs and interests that etiquette addresses. Experts in etiquette have a rich understanding of these needs and interests and of the ways in which etiquette satisfies them. Taking a rough stab, we might say that etiquette facilitates relationships between people, thereby minimizing overt aggression and hostility while preserving maximal dignity and comfort for all. ${ }^{28}$ When considering whether interrupting a phone solicitor is rude, one not only appropriately considers how the interruption affects this complex goal, but also how having phone solicitations as part of the social world affects it, as well as how deeming interruption rude will affect whether the social world will include phone solicitation.

Here is another situation, drawn from tort law, in which facts alone do not decide a blend concept's applicability. Sally is a sixteenyear-old delivery person for a local pizza parlor. She is mildly mentally retarded and attends a vocational school. The pizza parlor is located in a midsized city in the American northeast. On snowy evenings there is great demand for pizza delivery. On such nights, the roads have usually not yet been plowed properly. Parked cars usually line the streets. One such evening, Sally is on a delivery run, bringing pizza to a house facing the street. Following her usual practice, which is common among delivery persons in her city, she double parks in front of the house, rather than trying to negotiate the snow-filled driveway. She leaves the key of her truck in the ignition, with the engine running, while she runs to the door with the pizza. On this occasion, however, some neighborhood teenagers have spotted Sally's arrival. Once she has made it up the walk of the house, one of the

28. Even this very rough stab is likely to be quite contentious. Some would insist that etiquette has nothing to do with minimizing aggression and hostility or that it enables us to express these sentiments in relatively refined ways. Others would argue that conceiving of etiquette as a device for maximizing the comfort and dignity of ail is a comparatively modern notion, imbuing etiquette with a more democratic caste than it has had traditionally. The difficulty of specifying the underlying needs and interests addressed by etiquette - or any such rich evaluative taxonomy - illustrates one source of the interpretive scope we have when applying its blend concepts. A specification of the needs and interests addressed by an evaluative taxonomy is an interpretive product, open to dispute. 
teens, fourteen-year-old Alfred, hops into the truck and speeds away. Due to slippery road conditions, he makes it only half a block before the truck skids wildly, crashing into Edgar's parked car. The car is demolished. Alfred suffers severe injuries to both legs and his ribs. Both Edgar and Alfred sue the pizza parlor for which Sally works.

In the absence of highly similar factual precedent, deciding whether to apply negligence - or whether to apply the subsidiary concepts definitive of negligence, such as reasonable person and unreasonable risk - requires one to consult the evaluative points of those concepts. Consider the range of evaluative points informing reasonable person under like circumstances: allocation of blame, deterrence of unacceptable risktaking, and vindication of popular-moral intuitions about corrective justice and unacceptably dangerous behavior. Reasonable person responds to these evaluative points, within limits set by concern for judicial administrative efficiency. ${ }^{29}$ The decision about whether and how to apply the concept to Sally turns on how one's choice will or will not serve each of these points - points that, in any given case, may be in tension with one another..$^{30}$ When this is so, deciding application is that much trickier. Note that, particularly to the extent that one's choice serves the point of deterrence, it is appropriate to take into account whether one wants a world that allows sixteen-year-old, mildly retarded, novice drivers to deliver pizzas on snowy nights as quickly as they are able to do so by leaving their trucks parked on the street with the engine running.

In choosing or refusing to extend a blend concept's applicability in situations like these, in which facts alone do not clearly settle the matter, not only does one consult the evaluative point(s) of the concept, one also makes a judgment about what shape the social world should take. Insofar as one's decision becomes entrenched in the use of the blend concept in question, one will have influenced behavior and atti-

29. This list compiles the evaluative points suggested by typical, run-of-the-mill negligence cases. See, e.g., Galindo v. TMT Transp., Inc., 733 P.2d 631 (Ariz. Ct. App. 1986) (holding a paranoid schizophrenic to the usual reasonable person standard on grounds of deterrence and fairness); Goldstein v. Gontarz, 309 N.E.2d 196 (Mass. 1974) (permitting an "extreme care" instruction on the grounds that it led to a proper assessment of fault without undermining deterrence goals); O'Leary v. Jacob Miller Co., 473 N.E.2d 200 (Mass. App. Ct. 1985) (requiring the trial court to include some reference to circumstances when instructing the jury in negligence standard so as to assess properly the defendant's fault); Moning v. Alfono, 254 N.W.2d 759 (Mich. 1977) (finding that unreasonable risk is a matter of popular valuation); Meyers v. Robb, 267 N.W.2d 450 (Mich. App. Ct. 1978) (noting that unreasonable risk is a matter of social value); Goss v. Allen, 360 A.2d 388 (N.J. 1976) (holding a seventeen-year old to a modified reasonable person standard on grounds of fairness and safety).

30. Furthermore, we can debate whether negligence ought to respond to each of these evaluative points. See infra text accompanying notes $80-81$ (discussing controversies over what the evaluative points of negligence should be). 
tudes accordingly. Moreover, this is, presumably, one of the things that bore on the decision to extend or not to extend the concept in the first place. The appropriateness of taking into account how one wants the social world to be when deciding whether or not a particular blend concept applies has no counterpart when it comes to applying concepts such as proton or red. When deciding whether one can correctly apply proton to a particular set of facts, it is not appropriate to take into consideration how one wants the natural world to be. Nor is it appropriate to consider how one wants the world to be when deciding whether it would be correct to apply the concept red. But it is appropriate to acknowledge and take into account the way application is likely to influence the way things will go when deciding whether it would be correct to apply concepts like rude and negligence.

The application of a blend concept influences the way things will go because blend concepts often affect behavior, sentiment, or both. Although I have already rejected action-guidingness and anthropocentricity as marks of a blend concept, on grounds of both underinclusiveness and overinclusiveness, I do not deny connections between blend concepts and behavior and between blend concepts and sentiment. Yet these connections are not primary. They depend on the more fundamental connection between blend concepts and reasons. ${ }^{31}$

We consult blend concepts when we are seeking reasons about what to do, think, value, or believe. ${ }^{32}$ For instance, suppose you are trying to decide whether to interrupt a phone solicitor. One way to make the decision is to decide whether to do so is rude. If you make the judgment that interrupting is rude, you will have formulated a reason to refrain from interrupting. Or, suppose we are trying to decide whether to require Sally to compensate Edgar and Alfred. To do so, we will try to decide whether she was negligent. If we decide she was, we will have formulated a reason to require her to compensate.

Reasons arise from our needs and interests. We have reason to do, think, feel, believe, and value whatever satisfies our genuine needs and interests; we take ourselves to have reason to do, think, feel, believe, and value whatever we sincerely believe will actually satisfy what we regard as our genuine needs and interests. The reason-givingness of blend concepts originates with their responsiveness to what we regard as - and often are - our genuine needs and interests. ${ }^{33}$ It makes

31. Williams does note that thick concepts are characteristically related to reasons for action, but he proceeds to concentrate on action as the distinctive product of their application. WILliams, supra note 11 , at 140.

32. It is, however, a further question whether the reasons blend concepts provide are good, bad, conclusive, superficial, or powerful.

33. Here I set aside vexed issues such as the sources of genuine needs and interests and how 
sense for us to be guided in our actions, feelings, and beliefs by applications of concepts that satisfy what seem to be our needs and further our apparent interests.

Reason-givingness is reinforced by long-standing practices of usage. When a decision calls into play certain needs and interests, it then makes sense for people to figure out what to do by reference to the blend concept responsive to those needs and interests. Over time, people become so familiar with the concept and its typical applications that they do not necessarily go through the independent step of specifically identifying the underlying needs and interests; they simply decide whether or not the concept applies. In the background of the decision about interrupting the phone solicitor, for instance, is the interest in minimizing aggression and hostility while preserving maximal comfort and dignity for all. When wondering whether there is reason not to interrupt, one is, in a sense, wondering how best to serve this interest. Given that the concepts of etiquette respond to it, it makes sense to settle the question with reference to one of these concepts - that is, to figure out whether interrupting would be rude. In the long run, application may well take on a life of its own: while the concept remains responsive to the initial underlying needs and interests, distinctive fact patterns call for its application, perhaps reshaping the body of needs and interests, or our understanding of those needs and interests, to which the concept responds. At this point, the connection between a blend concept and its underlying needs and interests becomes a twoway street.

In addition to telling a coherent, justificatory story about how people have come to regard blend concepts as reason-giving, the needsand-interests account helps explain what is going on when a blend concept's reason-givingness gives way, either in a particular instance or across the board. Sometimes, despite a blend concept's usual reason-givingness, it seems to exert little or no reason-giving force. Jasper tells Elmo that what he is doing is rude; Elmo says "Yes, indeed it is" and goes right on doing it. Or, an American lawyer on holiday in a remote corner of the Amazon jungle says to his guide, "Lashing the cargo onto the raft that way is negligent," and the guide, agreeing, continues without a pause. The needs-and-interests account makes explanatory space for making sense of Elmo's or the guide's behavior, without sacrificing the ability to make sense of the blend concepts' more typical reason-givingness. The needs-and-interests account al-

to distinguish genuine needs and interests from spurious ones. We need not settle these issues to develop a general understanding of how blend concepts provide reasons that seem genuine to those who use them. In other words, we are concerned with felt reason-givingness. 
lows us to demonstrate that the background conditions in these cases are such that the needs and interests that usually inform rude or negligent are not present here, or that Elmo and the guide do not care about those needs and interests even if they are present. Furthermore, the needs-and-interests account gives Jasper and the lawyer the resources to object that the usual needs and interests do indeed obtain and to point them out, as well as the resources to criticize Elmo and the guide for failing to recognize or care about these needs and interests.

Even though we can always return to discussing the needs and interests that inform a blend concept, in many instances we will not need to nor will we do so. Applying the concept will be enough to supply a reason. This consequence of application is a distinctive trait of blend concepts. To see this, contrast the way in which a blend concept figures in a reason with the way in which a more purely descriptive concept, such as fire, figures in a reason. Although the fact that the building is on fire may well constitute a reason for leaving the building, we do not typically consult the concept fire when making ordinary decisions about whether to leave the building. Suppose you have no reason to think the building you are in is on fire, and you are trying to decide whether to leave the building. Deciding whether the building is on fire would be a rather roundabout way to approach the question. Fire plays a much more contingent role in reasons than does negligent or rude: it figures in one's reasons if one already has reason to believe it applies, but, without this background factor in place, one does not consult fire as a starting point from which to make decisions about what to do, think, feel, or believe. This is not to say there is nothing contingent about the reason-givingness of blend concepts; even when needs and interests that undergird its reason-givingness are wide and enduring, these needs and interests may still be, at some level, contingent. Nonetheless, the needs and interests that inform a blend concept, and blend concepts themselves, are entrenched deeply enough for blend concepts to play a distinctively pivotal role in arriving at reasons.

That blend concepts are reason-giving, combined with the tendency of reasons to influence the state of the social world, explains why we consider the effects of applying a blend concept when deciding whether to do so. But I mean to offer more than an explanation here; I mean also to defend the permissibility of considering how one wants the social world to be when deciding whether to apply a blend concept in a novel, and perhaps controversial, situation. More concretely, I am claiming that your knowledge of the ramifications of concluding 
that it is not rude to interrupt phone solicitors may appropriately influence your decision about whether interrupting phone solicitors is rude. Likewise, the knowledge that finding Sally's conduct negligent will discourage others from behaving as Sally did may appropriately influence the determination of whether she was negligent. The permissibility of considering how one wants the social world to be when applying blend concepts is another distinguishing feature of blend concepts. ${ }^{34}$

Admittedly, I have been oversimplifying. It is not, of course, appropriate to apply blend concepts simply according to one's whims, or even one's well-considered preferences, as to how the world should be, basing application solely on how its application affects one's personal goals. Although I will qualify my point, let me emphasize its lesson: when applying a blend concept, one appropriately acts from the interventionist stance toward the social world. Contrast this posture with the descriptivist stance appropriate when applying concepts belonging to the natural sciences or concepts of everyday representational talk. From within the interventionist stance, it is suitable to take into account a concept's reason-givingness when deciding whether and how to use it. Not only does the concept's world-guidedness not entirely dictate how it should be applied, but a correct response to this situation is consciously to base one's decision to apply the concept, at least in part, on the reasons that application will yield. From within the descriptivist stance, however, even when a concept's world-guidedness leaves a particular application up for grabs, it is not suitable to decide whether to use the concept on the basis of how its use will influence actions, valuings, and judgments. In a descriptivist stance, the correct response to the limits of world-guidedness is to seek more information about the state of the world or to withhold application of the concept.

Note that I am making overtly normative claims when I say that, in the case of blend concepts but not others, an interventionist stance is appropriate. I am not denying that one might try to use proton from an interventionist stance - perhaps deciding to apply proton to a mysterious unprotonlike phenomenon when reporting experimental results, in order to give the National Science Foundation reason to fund one's next grant proposal, or, perhaps less glaringly instrumentally, to give oneself a reason to continue to advocate one's pet theory. I am arguing that one of the things that makes it clear that proton is not a blend concept is that, when faced with a potentially controversial ap-

34. This permissibility may well seem obvious to contemporary legal thinkers, although it would not have seemed so in a more formalist, less instrumentalist era. 
plication of the concept, one's decision ought not depend on its implications for reasons, even if sometimes in actual fact such decisions do.

A word about mundane applications of blend concepts is in order here. So far I have been highlighting the appropriateness of the interventionist stance when applying blend concepts in controversial or novel circumstances. But the interventionist stance suits even run-ofthe-mill applications of blend concepts. Consider a prima facie uncontroversial, typical use of rude, such as the observation that it is rude for an adult to wipe his runny nose on his sleeve in front of others when there is a tissue at hand. Part of what makes such a case uncontroversial is that the matter of whether we want people to behave in this way is already settled. It is not that this use of rude is not from the interventionist stance; it is that the goal of the interventionism is already established and uncontentious. The acceptability of discouraging using one's sleeve as a handkerchief turns on some other, prima facie uncontroversial premises underlying the use of rude under consideration, namely that rude behavior is worth less than polite behavior and that the way to handle intimate bodily functions, particularly those related to secretions, falls under the jurisdiction of etiquette. In other words, the mundane application of the concept rude here turns on the settled place of rude in an evaluative taxonomy that uncontroversially covers the central facts of the situation at hand. Or consider the uncontroversial judgment that it is negligent, other things equal, for a drunken doctor to perform surgery. Again, the goal of the interventionism that is indeed in play here is widely accepted: to avoid having drunken surgeons perform operations. Tort law's jurisdiction over this kind of conduct is also well established. What distinguishes a run-of-the-mill use of a blend concept from more problematic ones is uncertainty or controversy over the goal sought, the relationship between the evaluative taxonomy and the facts at hand, or the place of the candidate concept within the evaluative taxonomy to which it belongs. None of these variables - goal, relationship between evaluative taxonomy and the world, or relations between the categories of the taxonomy - exclusively governs appropriate application of a blend concept. Furthermore, none is a matter of sheer personal preference.

Despite the interventionist stance apt for the use of blend concepts, their application is not entirely goal driven. Both their world-guidedness and the nature of their reason-givingness preclude this. Blend concepts are world-guided, and their world-guidedness has a normative quality to it. This means that their application is, to an extent, governed by facts about the world that have little or nothing to do with how a particular user of the concept wants the world to be. This 
is why, under some circumstances, refusal to use - or insistence upon using - a blend concept seems odd, misguided, or downright mistaken. It just is not proper to consider someone who says "Please pass the salt" at a meal rude; nor is it proper to refuse to consider rude a healthy adult who takes food from everyone's plate with his hands and without asking permission. More glaringly, it is strange, as well as improper, to consider someone rude for sitting and taking a law school exam along with his classmates. These examples are not to deny that one can sometimes unusually apply a blend concept to great effect for example, "That pianist's rendition of ___ was downright rude" - but the efficacy of such applications generally turns on their sensitive, sometimes intricate, connection to the concept's basic worldguidedness. What the examples indicate is that one cannot properly use rude just because one wants others to stop saying "Please pass the salt" or to stop taking law school exams or to eat off of others' plates. Similarly, one cannot properly call any old behavior negligent, no matter how much one wants to deter that behavior. It may be rude for an adult to wipe his runny nose on his sleeve in front of others when there is a tissue at hand, but, fanciful circumstances not prevailing, it is not negligent. Facts like the ones specified simply do not license use of the concept. The world-guidedness of a blend concept restricts the extent to which its application can be goal-driven.

This restriction is important. Without it, the reason-givingness of a blend concept would be undone. Blend concepts derive their reasongivingness from their place within the evaluative taxonomies to which they belong. These taxonomies are responsive to specific human needs and interests, which they serve by categorizing the world in a particular way. The blend concepts that demarcate the categories of an evaluative taxonomy are reason-giving because they serve the evaluative point of the taxonomy. Now, suppose it were acceptable to "borrow" a blend concept's reason-givingness to serve any given interventionist goal. Suppose one insisted on applying rude to the act of taking law school exams in an effort to eliminate this behavior or insisted on applying negligent to the sleeve-wiping adult to discourage that activity. Unless one could give a good account of how these applications of rude and negligent vindicate the evaluative point(s) of etiquette and tort law, were one to persist in the proposed applications, one would be likely to undermine the concepts' reason-givingness. Others are likely to see through persistent, puzzling applications of a blend concept and then to become suspicious of its reason-givingness even in more typical applications.

This last point brings us to another crucial feature of blend con- 
cepts: they are community property. Neither their goal-directedness, their membership in an evaluative taxonomy, nor the structure of that taxonomy and the way it carves the world is a private matter. The social nature of blend concepts stems from the social nature of taxonomies of worth to which they belong. Such taxonomies are social goods; they reflect evaluations of merit shared, to some significant extent, amongst community members, rather than pure personal preferences. Regardless of their metaphysical foundation, taxonomies of worth lay out evaluative distinctions shared within a community; blend concepts are used by members to influence themselves and one another. ${ }^{35}$ It is not surprising, then, that the facts that guide the application of a blend concept are often social facts - facts constituted by social practices, conventional mores, shared cultural ideas, community values, and customs, all facts that often are best described in terms of further blend concepts. Nor is it surprising that the application of a blend concept often has a social impact, affecting how others value, judge, and act.

The successful user of a blend concept - someone who applies it surefootedly in mundane cases and convincingly in novel or controversial ones - is well aware of the interdependence of a blend concept's world-guidedness and reason-givingness. Such awareness is critical to the process of persuading others to accept a novel use of a blend concept. Unless one appreciates the way in which a blend concept's world-guidedness is shaped by its reason-givingness and vice versa, one cannot distinguish brute factual analogies from more attenuated ones nor articulate sophisticated interpretations of a blend concept's place in an evaluative taxonomy or of that taxonomy's evaluative point. One needs to be able to explain to others, in a compelling way, why extending the application of a blend concept will not undermine its reason-givingness or why its reason-givingness is of the variety salient to the newly encountered situation. ${ }^{36}$

35. This is not to say that a community member cannot criticize or reject a particular taxonomy or category within it, see infra text accompanying notes $37-39$, but to remark that to do so is to attack community property.

36. It is the interdependence of a blend concept's world-guidedness and reason-givingness that cuts against the kind of analysis advocated by H.L.A. Hart or, from the philosophical side, R.M. Hare. Both Hart and Hare push analyses that would treat a blend concept as one that implicitly summarizes the facts that make a blend judgment apt and implicitly states a prescriptive rule requiring certain consequences if those facts obtain. See HARE, supra note 11, at 56-62; Hart, supra note 12, at 43 . In a Hart- or Hare-like analysis, these tasks are logically independent of one another, although blend concepts perform them simultaneously. Let us call such analyses "prescriptivist," as Hare's position is known in the philosophical literature. JÜRGEN HABERMAS, Discourse Ethics: Notes on a Program of Philosophical Justification, in MORAL CONSCIOUSNESS AND COMMUNICATIVE ACTION 55 (Christian Lenhardt \& Shierry W. Nicholsen eds., 1990); R.M. HARE, Freedom and ReasoN $\$ \S 2.6-2.8$ (1963); R.M. HARe, Moral Thinking 52, 228 (1981); Williams, supra note 11, at 82. The forgoing discussion in the text 
One who possesses sensitive awareness and understanding of the way in which a particular blend concept's world-guidedness and reason-givingness interrelate has "gotten" or "grasped" the concept. Note that I do not argue that, in order to "get" or "grasp" a blend concept, one must endorse the valuing, make the judgment, or perform the act for which the concept's application gives reason; nor do I hold that one must be motivated toward endorsing the valuing, making the judgment, or performing the act. Rather, one must understand in what respects the concept is reason-giving. That is, one must understand its role in the overall responsiveness to some set of human needs and interests displayed by the taxonomy of worth to which the blend concept belongs. Evidence that one has "gotten" a blend concept consists in the ability to use blend concepts in ways that are plausible to other users, particularly in novel or controversial situations. Such deft usage enhances the concept's usefulness in making distinctions of worth and further entrenches the concept in the social context.

How far "inside" or "outside" a culture one must be to grasp a blend concept depends upon the needs and interests that inform the taxonomy of worth to which the concept belongs. It seems possible, even plausible, that to recognize and understand some needs and interests takes a great deal of cultural information and insight, including some that one could not acquire without a fairly significant immersion in the relevant culture. Of course, not all needs and interests are like this. Generally speaking, however, grasping a blend concept will require some degree of immersion: to wit, the need for the novice to immerse herself in caselaw to learn how to use negligence deftly; likewise, the impossibility of extracting a conclusive formula or algorithm for the deft usage of negligence. While there is no blanket rule stipulating how one must be located vis-à-vis a particular culture in order to grasp its blend concepts, grasping a sophisticated blend concept will often require cultural knowledge and insight of a kind best gained through fairly intimate acquaintance with the relevant culture.

Everything I have said about blend concepts so far applies to blend

illustrates the shortcomings of a prescriptivist account of the use of blend concepts. Prescriptivism might be telling the correct story about the logic of the content of blend concepts, but such a story will not make sense of what the use of such concepts involves. If blend concepts simply implicitly summarize facts and state prescriptive rules, then facts alone would always settle the issue of a blend concept's applicability. But if, as I have argued, deciding applicability appropriately requires sensitivity to the evaluative aspect of a blend concept, the prescriptivist has not made sense of the way in which application of blend concepts is world-guided because understanding a blend concept's world-guidedness is not simply a matter of ascertaining some nonevaluatively delineated set of descriptive conditions. Personally, I doubt that prescriptivism even has the correct analysis of the logic of the content of blend concepts. Even if the distinction between content and use holds up, I think an adequate analysis of the content of blend concepts will not diverge as sharply from an adequate account of their use as does prescriptivist analysis. 
concepts one finds distasteful or repugnant. Certain racist and sexist epithets qualify as blend concepts. Bitch and Jewish American Princess (J.A.P.) are world-guided, reason-giving members of taxonomies of worth that respond to particular human needs and interests. Grasping these concepts so as to be able to apply them deftly in novel or controversial situations does require a sensitive understanding of their role in responding to these needs and interests. Under just what circumstances will users of J.A.P. apply it? To an observant Jew who is poor but has expensive tastes? To someone whose parents and ancestors were practicing Jews but who has converted to Protestantism and wears lots of gold jewelry and slightly flashy clothes? But just because a concept qualifies as a blend concept - and its reason-givingness must therefore be acknowledged - does not mean that one must use the concept. One might well refrain from using a distasteful or repugnant blend concept precisely because it is reason-giving, but in ways one wishes to reject. By the same token, one might discourage others from using the repugnant blend concept - or even insist that they do not. Whether a blend concept is repugnant or not is a substantive question in its own right, independent of the question of whether it is a blend concept.

Rather than questioning or attacking any particular application of a blend concept, one can criticize repugnant or distasteful blend concepts. One way to do so is to demonstrate the spuriousness or ugliness of the needs and interests that animate the taxonomy of worth to which the concept belongs. This strategy assails the parent taxonomy in order to undo the child concept. One can argue that bitch is part of a taxonomy of misogynist evaluation that answers to an interest in subjugating women, an interest that does not merit attention. One can argue that J.A.P. belongs to a taxonomy of racist and sexist evaluations that serves the needs of certain empowered groups by inflaming racist and sexist tendencies; such needs ought not be addressed by the disempowered, who should resist the distractions of succumbing to racism. One can argue, as Morton Horwitz does, that negligence is part of a taxonomy animated by the interests of capitalists, ${ }^{37}$ and one might further argue that these interests do not merit service. Another way to criticize a blend concept is to accept or endorse the relevant needs and interests but to deny that the concept plays a role in responding to these or that it does not play its putative role well. Consider, for example, the concept macho. This concept belongs (arguably) to a taxonomy of masculine worth that serves an (arguably) important interest

37. Morton J. HoRwitz, The Transformation of American LAw, 1780-1860, at 85108 (1977). 
in delineating virtues and vices that are (arguably) especially salient to men in our society. One might maintain that macho carries too much conflicting baggage to perform satisfactorily as a member of such a taxonomy and that this baggage cannot be sorted to render the concept helpful. Macho applies to a complicated combination of traits some valuable, others not - so it is hard to tell if macho delineates a virtue or a vice. One might argue that such an ambiguous concept does not contribute helpfully to a taxonomy of masculine worth.

The forgoing illustrations do not exhaust the ways in which one might criticize a blend concept. I selected them to teach an important lesson. Often, the most pungent criticism of a blend concept requires an intimate grasp of it. To condemn the needs and interests animating a blend concept's home taxonomy requires a sensitive understanding of both the taxonomy and its evaluative point. To criticize the role or performance of a blend concept requires both this kind of understanding and a sensitive awareness of the place and function of the concept within the home taxonomy.

The lesson that the power of one's criticism often varies with the extent of one's grasp of a blend concept has a corollary: in coming to grasp a blend concept, one may ultimately turn against it. Sometimes familiarity breeds contempt. As one becomes intimately aware of the needs and interests animating a taxonomy of worth, the role a particular concept plays in addressing them, and the way in which the concept performs its part, one may come to question the taxonomy or the concept. Eventually, one may reject one or both. That this can happen testifies to the difference between grasping and merely using a blend concept. Although this is ultimately an empirical question, it seems safe to assume that one need not have that sophisticated a grasp of a blend concept to use it uncontroversially in routine cases. One should be able to do this simply by mimicking other users. If one has grasped a blend concept, however, one is able to use it convincingly in novel or controversial situations. In such situations, mimicry obviously will not suffice. At such moments, those who merely use a blend concept will falter; those who grasp it will not. ${ }^{38}$

Coming to see that a blend concept is repugnant or distasteful may well necessitate a reflective, conscious grasp of the concept. Noticing what is wrong with a blend concept might take more than great familiarity with the relevant taxonomy of worth, its evaluative point, and so forth. One who possesses such familiarity might well be able to apply

38. I am not suggesting that the latter will automatically apply the concept convincingly, just that they are likely to be able to figure out a way to go on that other users will accept. 
the concept convincingly in novel or controversial cases, thereby evidencing a grasp on the concept. Familiarity does not invariably breed contempt, however. In fact, familiarity sometimes makes it hard to see things as they really are. Moreover, being familiar with a taxonomy and its evaluative point is not the same as having a conscious, reflective understanding of it. This kind of understanding can bring out features of the taxonomy that one had not previously noticed, features that problematize the taxonomy, its member concept(s), or both. Consider a regular user of intellectual, one who is intimately familiar with the concept and the relevant taxonomy of worth. Suppose she faces a novel situation in which she finds herself unwilling to apply the concept to a person whose intelligence she respects tremendously. She might be inspired to reflect upon the concept, the relevant taxonomy of worth, its evaluative point, and so forth. She might examine carefully, perhaps for the first time, the needs and interests that inform the taxonomy of worth to which intellectual belongs. It is possible that she would discover that these include some needs and interests she had not consciously noticed before, such as an interest in perpetuating elitism. If, after developing a reflective grasp on the concept intellectual, she rejects the needs and interests to which it responds, she may decide to abandon the concept. ${ }^{39}$

There are other stories to tell about how one might come to have a reflective grasp on a blend concept and thereby see it in a different light. Whatever the story, none represents a guaranteed method for bringing people to realize the repugnance of a repugnant blend concept - but a reflective grasp on a blend concept with which one is deeply familiar can change one's understanding of it.

Similarly, a reflective grasp on a concept not previously regarded as a blend concept might lead one to recognize that it is in fact such a concept. Some would argue, for example, that a reflective grasp on psychological concepts would reveal them to be blend concepts. This brings us back to schizophrenic. There is a debate about whether and what kind of valuation enters into social science. One camp maintains that distinctions of worth are part and parcel of the enterprise. ${ }^{40}$ Suppose this is right, but not readily apparent to many who use psycho-

39. Of course, she might also decide to embrace the newly noticed needs and interests, or she might try to reform the concept rather than abandon it. Without fleshing out the example more fully, we can neither predict nor recommend a response.

40. Of course, this camp's position is far more intricate and sophisticated than this. For the full-blown view, see TAYLOR, Interpretation, supra note 11; Peter Winch, The Idea of a Social Science, in Rationality 1 (Bryan R. Wilson ed., 1970). For an example of one who takes this position specifically with regard to psychological concepts, see R.D. LAING, THE DIVIDED SELF (1960). 
logical concepts often and skillfully. ${ }^{41}$ Developing a reflective grasp on these concepts might show such users that the concepts make up an evaluative taxonomy, whose member concepts they apply from an interventionist stance, in accordance with both their world-guided and reason-giving elements. This could shift these users' conception of psychology and the other social sciences. On the other hand, those who hold that distinctions of worth do and should figure prominently in social science might be mistaken. One who wanted to show this might vindicate the correctness of the descriptive stance for the application of psychological concepts, demonstrate that the taxonomy of psychological concepts has an exclusively explanatory point, and so on. Without further investigation, I could not take a stand in this debate. What I have tried to do here is sketch how one might plausibly come to recognize schizophrenic as a blend concept. The plausibility of this possibility agrees with my intuition that schizophrenic need not clearly fall outside an acceptable delineation of blend concepts, as should chair and proton.

So far I have discussed the ways in which a reflective grasp on a blend concept can lead to recognition or rejection. In these cases, one works from the concept, so to speak, toward a conscious understanding of the human needs and interests to which it responds. Sometimes one is disgusted by what one discovers upon acquiring this understanding; sometimes one is edified. In another kind of case, the path from concept to conscious understanding of human needs and interests is followed - but in reverse. In these instances, a reflective awareness of a set of human needs and interests enables, and perhaps spurs, one to engineer a taxonomy of worth so as to yield the evaluative power with which to address those needs and interests. In the extreme case, one starts this task from scratch. In the simplest case, one tinkers with a concept already part of a long-standing taxonomy of worth. Somewhere in between are the cases in which one takes a blend or quasi-blend concept already current in the culture and consciously cultivates it as a blend concept, perhaps by articulating more clearly the latent taxonomy of worth to which it belongs or the role it could play in that taxonomy. Many "technical" concepts or "terms of art" are engineered blend concepts. Negligence and its sister concepts are examples of blend concepts that appear in nonlegal discourse and

41. Perhaps their training obscured the evaluative aspect of the concepts they were learning to use. The possibility that training can be effective without making that aspect clear raises a number of other possibilities. It might well be the case that training in the use of a blend concept, even training intended to result in a reflective grasp of the concept, is best effected by reserving overt instruction as to the evaluative aspect of the concept until the learner has, through mimicry, mastered very ordinary usage. 
then receive conscious cultivation from legal specialists, including courts, lawyers, and legal scholars. The cultivated term of art responds to the needs and interests that inform negligence in a more refined and powerful way than does its uncultivated ordinary language counterpart.

When cultivating a blend concept, one consciously and explicitly designs its world-guidedness and reason-givingness so that it can perform effectively in responding to the needs and interests that inspired the effort in the first place. Shaping the concept suitably is one step toward ensuring that it catches on. One cannot, however, just select any old needs and interests to address. A distinguishing feature of blend concepts is that they belong to taxonomies of worth that purport to respond to communally endorsed needs and interests, as opposed to purely private or personal needs and interests. To engineer a blend concept successfully one must embed it in a taxonomy that at least apparently responds to needs and interests communally endorsed by a group of potential users. So, for example, one evaluative point of tort law is the vindication of popular-moral intuitions about corrective justice and unacceptably dangerous behavior. Negligence and related tort concepts speak to the interests latent in these popular-moral intuitions; hence negligence maintains its reason-givingness in its capacity as a term of art.

Some blend concepts merely purport to respond to communally endorsed needs and interests. Racial and sexual epithets, for example, purport to be responsive to communally endorsed needs and interests, but the needs and interests they actually address are not in fact communally endorsed - assuming that the community in question includes members of the disfavored racial or ethnic group. This assumption may well be questionable. Use of racial and sexual epithets often represents an effort to define the boundaries of community. Community boundaries, however, are subject to debate. One way to criticize a racist, sexist, or other blend concept would be to show that the needs and interests to which it purports to respond are not actually communally endorsed because the community does not in fact endorse them. Another way would be to show that those who communally endorse them do not really comprise the community. In the end, to complete our account of how to criticize and defend blend concepts, we need a story about how to define communities. This story will be complicated by the fact that blend concepts play a role in the process of community definition. Although I will not attempt this story here, I want to emphasize that blend concepts purport to live up to communally endorsed needs and interests. In Part II, I will argue that the 
failure of a blend concept to deliver on this promise sharply stunts its capacity to figure in objective judgments.

Before turning to the issue of objectivity, I would like to emphasize a theme that runs throughout my characterization of blend concepts: their social nature. Blend concepts are social in the following interrelated and mutually supporting respects.

1. They tend to be world-guided by social facts, such as conventional mores, shared cultural ideas, community values, and customs.

2. Their application affects the social world, and it is appropriate to take this into account when deciding whether to apply a blend concept in a new or controversial case.

3. They belong to taxonomies of worth that reflect intersubjective evaluations of merit, not just personal preferences.

4. They purport responsiveness to communally endorsed needs and interests.

Vindicating this multifaceted social nature is, as I shall argue in Part II, essential to the objectivity of a blend judgment.

\section{OBJECTIVITY}

Critics of the concept of objectivity sometimes write as if it is a bad concept because it can never answer to our demands of it. Catharine MacKinnon, for example, argues that "women's interest lies in overthrowing the distinction [between subjective and objective] itself." 42 Or they skeptically question particular applications of the concept in a way that suggests an overall distrust of it. MacKinnon continues, "[f]eminism does not see its view as subjective, partial, or undetermined but as a critique of the purported generality, disinterestedness, and universality of previous accounts." 43 Duncan Kennedy writes about the "initial apparent objectivity of [an] objectionable [legal] rule": "from my point of view the application of the rule to this case feels like a nondiscretionary, necessary, compulsory procedure." $44 \mathrm{He}$ goes on to call this "the pseudo-objectivity of the rule-as-applied."45 Richard Delgado speaks of critical race theory's "distrust of law's neutral and objective facade." 46

Criticisms such as these indicate what we want out of objectivity: a contrast from the arbitrary, the whimsical, the idiosyncratic, the purely personal. We want the objective not to be - in a word subjective, as in the dismissive comment, "Well, you're just being sub-

\footnotetext{
42. MACKINNON, supra note 1 , at $120-21$.

43. Id. at 121.

44. Kennedy, supra note 5 , at 520 .

45. Id. at 522.

46. Delgado, supra note 1 , at 744 .
} 
jective about this." The reason this comment is dismissive is that, in the situations in which such a comment is at all appropriate, we feel entitled to ignore a judgment on the ground of its subjectivity. On the other hand, sometimes we feel that we ourselves or others are not entitled to ignore or flout certain judgments. We feel that some judgments exert interpersonal validity, even with regard to individuals who do not agree with or accept them. Our concern for interpersonal validity, and hence objectivity, varies from context to context. In any case, in a variety of contexts there are some judgments for which we think that we can give reasons that would sustain their interpersonal validity and hence preserve them from being arbitrary, whimsical, idiosyncratic, or purely personal.

From these desires, feelings, and thoughts a concept of objectivity emerges, according to which the objective is that which possesses interpersonal validity by virtue of the reasons in its favor. This delineation of the concept is quite abstract and, therefore, elastic. I consider this an advantage because of the diversity of kinds of judgments whose objectivity we measure. But the abstraction and elasticity pose a concomitant disadvantage: by itself, the concept of objectivity tells us very little about what it takes for a specific type of judgment to be objective. For this task, we need specific conceptions of objectivity, conceptions suitable for the types of judgment in question. ${ }^{47} \mathrm{~A}$ conception of objectivity suitable for a certain kind of judgment should tell us why interpersonal validity matters in the context for which the conception is suitable, and what it takes for a judgment of that kind to exert interpersonal validity. The answers to these two questions will be intimately connected.

In this Part, I develop a conception of objectivity suitable for blend judgments. I accomplish this via exploration of alternative conceptions of objectivity that are suitable for scientific and moral or political judgments. I consider their adequacy as models for a conception of objectivity suitable for blend judgments. I conclude that neither scientific nor moral-rationalist conceptions of objectivity can serve as is,

47. Often those writing about objectivity fail to distinguish between the concept of objectivity and more particular conceptions of it. Kent Greenawalt's recent book provides an example. See KENT GREENAWALT, LAW AND OBJECTIVITY 3-7 (1992). Greenawalt surveys a number of (what I would call) different conceptions of objectivity and considers whether any or all are suitable to law. Among the conceptions he discusses are objectivity as determinacy of rules, see id. at 11-89, objectivity as impartial treatment, see id. at 93-159, and objectivity as moral, political, or economic rightness. See id. at 163-235. Greenawalt's survey seems rather disjointed, in part because he does not identify the concept of objectivity that would unify the various conceptions he considers. He also does not consider whether different conceptions might be more or less suitable to different kinds of legal judgments, depending on the type of concept applied in each kind. Not all legal judgments apply blend concepts. The conception of objectivity I develop here is suitable for blend legal judgments but may well not be suitable for other kinds. 
although they provide insight into what such a conception of objectivity must include. After articulating the blend conception of objectivity, I then use it as a regulative ideal against which to measure the objectivity of specific blend judgments, demonstrating the critical bite of the blend conception. Finally, I argue that the blend conception's pragmatic orientation makes it a practically workable regulative ideal.

I should emphasize from the outset that the blend conception of objectivity, which specifies a set of conditions for objectivity in blend judgments, is not a pure proceduralist conception: it does not specify a procedure that, simply by virtue of its operation, renders the outcome - whatever it might be - objective. 48 Rather, it provides a reliable heuristic for generating objective blend judgments, including objective blend legal judgments. The conditions specified by the blend conception are neither necessary nor sufficient for objectivity in blend judgment - that is, a legal judgment might be interpersonally valid by virtue of the reasons in its favor even if it has not been arrived at through a process that fulfills these conditions, and the process is not a guarantee that the judgment will be interpersonally valid by virtue of the reasons in its favor. Nonetheless, if the conditions specified by the blend conception are fulfilled in the process of coming to a legal judgment, then it is very likely that the judgment will possess a high degree of objectivity.

\section{A. Scientific and Moral-Rationalist Conceptions of Objectivity}

There is more than one scientific conception of objectivity, which is to say that there is disagreement over what it takes for a scientific judgment to exert interpersonal validity. The different scientific conceptions fall into two categories, ontological and methodological. At the heart of a scientific-ontological conception of objectivity lies the idea that a scientific judgment is objective insofar as it corresponds to facts about the world, facts that obtain regardless of the scientists themselves. In this kind of conception, objective scientific judgments exert interpersonal validity because, despite variations in individual beliefs, goals, or desires, the facts that make a scientific judgment objective remain the same. ${ }^{49}$ Given that the goal of science is prediction

48. A lottery is an example of a pure proceduralist device: whatever number is chosen by the established selection procedure is, by definition, the winner. There is no independent criterion for defining the winning number.

49. Peter Railton advances this conception of objectivity. Peter Railton, Marx and the Objectivity of Science, in THE PHILOSOPHY OF SCIENCE 763 (Richard Boyd et al. eds., 1991). Railton presents the scientific-ontological conception as an epistemically externalist conception. According to his account, a scientific judgment's objectivity does not depend upon whether the scientist who holds the judgment is aware of the facts that make it objective. One could present a more epistemically internalist scientific-ontological conception by adding to the requirement of 
and control of the natural world, it makes sense for different scientists, whatever differences in belief, goal, or desire they may have, to accept objective scientific judgments because scientific-ontologically objective judgments track that world and are therefore helpful in predicting and controlling it.

Proponents of scientific-methodological conceptions of objectivity agree that prediction and control of the natural world is a major goal of science, but they deny that objectivity in scientific judgment is a matter of correspondence to facts that obtain regardless of the scientist's beliefs, goals, desires, or representations of the facts themselves. ${ }^{50}$ According to an individualist scientific-methodological conception, a scientific judgment is objective when it is the product of a method that publicly tests interpersonally comprehensible hypotheses against observational, experiential data. This conception is individualist because the method it recommends can, in principle, be performed by a single individual, working alone. ${ }^{51}$ An alternative scientific-methodological conception is more socialist. A socialist scientific-methodological conception incorporates the individualist conception of objectivity but adds to it a requirement that, for a scientific judgment to be objective, the judgment, its background theoretical assertions, hypotheses, and assumptions, and the interpretation of its supporting data must all be proffered for and receive public scrutiny and criticism from diverse quarters. ${ }^{52}$ For both individualist and socialist scientific-methodological conceptions, publicity is the cornerstone of objectivity. The socialist conception, however, requires collective participation, whereas the

correspondence a requirement that a scientist who holds the judgment in question must also be aware of this correspondence.

50. Note that advocates of scientific-methodological conceptions can consistently maintain that the truth of a scientific judgment, even if not its objectivity, is a matter of correspondence to facts that obtain regardless of the scientist's beliefs, goals, desires, or representations of the facts themselves.

51. Representatives of the individualist scientific-methodological camp include Carl Hempel and Bas van Fraassen. See, e.g., CARL HeMPEL, Aspects of ScIENTIFIC ExPLANATION AND Other Essays in the Philosophy of Science 141 (1965); Bas C. van FraAssen, The SCIENTIFIC IMAGE 82 (1980).

52. Feminist philosophy of science has produced the strongest proponents of socialist scientific-methodological conceptions. These include Sandra Harding, Helen Longino, and Lynn Nelson. See Harding, supra note 1, at 105-37, 150; Helen LONGINo, Science as Social KNowledge $62-82$ (1990); Helen Longino, Essential Tensions-Phase Two: Feminist, Philosophical, and Social Studies of Science, in A MIND OF ONE's OWN 157-72 (Louise M. Antony \& Charlotte Witt eds., 1993); LyNN H. Nelson, Who KNows: From Quine to A FEMINIST EMPIRICISM 43-81, 255-99 (1990). Longino emphasizes the necessity of "recognized avenues for criticism," such as journals, conferences, and the institution of peer review, all of which provide arenas for public scrutiny and criticism. LoNGINO, supra, at 76. Harding, who writes from a different wing of feminist philosophy, emphasizes the need to study scientifically background cultural beliefs and assumptions about different individuals and groups who participate in scientific inquiry. HARDING, supra note 1 , at 149. 
individualist conception does not. On either conception, the publicity of objective judgments lends them interpersonal validity because publicity helps ensure that scientific judgments adequately explain empirical appearances, whatever theories, norms, values, beliefs, or desires inform a particular scientist's judgments. ${ }^{53}$ Empirical adequacy facilitates prediction and control of natural phenomena; objective judgments thereby serve the central scientific goal. Thus, it makes sense for them to exert interpersonal validity amongst scientists and others who share a belief in the goals of science.

For present purposes, we need not settle the question of which scientific conception of objectivity is most suitable for scientific judgments. Although the scientific conceptions can help us delineate the specifications of the blend conception of objectivity, ${ }^{54}$ at this point we need to see why scientific conceptions do not provide a conception of objectivity suitable to blend judgments. In both the scientific-ontological and scientific-methodological conceptions, a judgment's interpersonal validity depends upon its service to the goal of prediction and control of natural phenomena. On the scientific-ontological conception, correspondence to the natural world is the reason an objective scientific judgment exerts interpersonal validity. On the scientificmethodological conceptions, satisfying some kind of publicity requirement is the reason an objective scientific judgment exerts interpersonal validity. Although the mechanism of service is different according to the two types of scientific objectivity, in each of them objective judgments exert interpersonal validity because they serve the goal of prediction and control of natural phenomena. This is not the goal, however, in domains such as law, etiquette, humor, and aesthetics, in which we apply blend concepts. So a conception of objectivity premised on that goal makes little sense for blend judgments, which, unlike scientific ones, are not from the descriptivist stance made efficacious for prediction and control. ${ }^{55}$ Notice that, even on the scien-

53. Some advocates of scientific-methodological conceptions, such as Hempel and Longino, are realists; they take empirical adequacy to warrant ontological inferences about how the natural world is, independent of particular theories, norms, values or beliefs and desires. Others, like van Fraassen, are instrumentalists and reject such inferences. Note that, regardless of whether or not they are instrumentalists, scientific-methodological proponents advocate epistemically internalist conceptions of objectivity: those executing a scientific method that is sufficiently public to confer objectivity will be consciously applying procedures with the power to do this, creating an internalist connection between objectivity and awareness of what makes certain judgments objective.

54. See infra text accompanying notes 72-77.

55. It is the unsuitability of a scientific-ontological conception to blend judgments that seems to prompt Bernard Williams's conclusion that converged-upon scientific judgments are objective whereas converged-upon thick ethical judgments are unlikely to be objective. WILliams, supra note 11, at 151-53. When he discusses scientific judgments, Williams appears to have in mind a 
tific-ontological conception, correspondence to natural fact is not, in itself, constitutive of objectivity. Correspondence amounts to objectivity, on that conception, because correspondence creates interpersonal validity by facilitating prediction and control. Even the scientificontological conception, then, does not treat objectivity simply as a matter of metaphysics.

If scientific conceptions of objectivity do not provide ready-made models for a conception of blend objectivity, perhaps moral-rationalist conceptions do. According to moral-rationalist conceptions of objectivity, a moral or political judgment is objective when a specified group of people - the specification varies from version to version - largely agrees upon it or would largely agree upon it; again, views as to whether agreement must be actual or may be hypothetical vary. ${ }^{56} \mathrm{Ac}-$ cording to such conceptions, agreed-upon moral and political judgments exert interpersonal validity because agreement signals that they are acceptable to the individual members of the specified group. This means that agreed-upon moral and political judgments serve the end of coordinating action in mutually acceptable fashion, without resort to force and violence - a major goal of morality and politics according to certain leading accounts. ${ }^{57}$

As do scientific conceptions of objectivity, moral-rationalist conceptions fall into two categories. They can be dialogical or monological. I will consider Jürgen Habermas's dialogical moral-rationalist conception of objectivity and then John Rawls's monological moralrationalist conception. Habermas delivers an account of when "purer" normative judgments of what ought to be done qualify as objective. ${ }^{58}$ He maintains that discourse of a certain kind - which he labels "argumentation"59 — produces objectivity. In other words, a

scientific-ontological conception of their objectivity. Id. at 136, 152. Due to the scientific-ontological conception's unsuitability for thick judgments, it makes sense that, when measured by this conception, thick judgments fail to seem objective. Williams himself suggests an alternative, Aristotelian conception of objectivity that, he concedes, might show how thick ethical judgments could be objective, but he doubts that such a conception can in fact be developed. Id. at 152-55. The blend conception of objectivity I advance later in this chapter is nothing like the Aristotelian conception to which Williams refers.

56. Jürgen Habermas and John Rawls each deliver versions of the moral-rationalist conception of objectivity. Both consider agreement (actual, in the case of Habermas; hypothetical, in the case of Rawls) essential to objectivity. HABERMAS, supra note 36, at 65; JoHN RAWLS, Political Liberalism 112, 119 (1993).

57. Contemporary representatives include Allan Gibbard and John Rawls. See GibBard, supra note 11, at 322-25; RAWLS, supra note 56, at 8-11; JoHN RAWLS, A THEORY OF JUSTICE 3-6 (1971).

58. I use the term purer normative judgments to refer to judgments that apply normative concepts that are significantly less or less directly - some would argue, not at all - worldguided than are blend concepts. Ought is such a concept.

59. HABERMAS, supra note 36 , at $44,45-47,57-68$. 
judgment is objective if and only if it is reached through the process of argumentation. Argumentation is the process of publicly and collectively providing reasons for and against a judgment. Public provision of reasons ensures that the judgment is the product of a rational, genuine consensus rather than the outcome of strategic manipulation. The ground rules for argumentation are: (1) every competent speakeractor is allowed to participate; (2) everyone is allowed to question, to introduce any assertion, or both and to express his attitude, desires, and needs; and (3) no speaker may be prevented, by any form of coercion, from exercising the rights specified in the first two ground rules. These ground rules presuppose that objectivity consists in satisfying principle $U$ : "All affected can accept the consequences and the side effects its general observance can be anticipated to have for the satisfaction of everyone's interests (and these consequences are preferred to those of known alternative possibilities for regulation)."60

Habermas's dialogical moral-rationalist conception suffers from a number of problems. To start with a relatively minor one, the "transcendental-pragmatic" argument Habermas advances in favor of $U$ does not wash. Habermas argues that anybody attempting to dispute $U$ via argumentation finds herself presupposing $U$. That is, so long as the opponent of $U$ takes herself to be voicing her opposition within a process oriented toward genuine understanding and consensus, she must be regarding herself as abiding by the ground rules that in fact build $U$ into the foundation of practical discourse. The two most prominent difficulties with Habermas's defense of $U$ against the skeptic lie in his arguably questionable characterization of argumentation and his inadequate response to the skeptic who rejects $U$ via some nonargumentative mechanism. Habermas's conception of argumentation rules out repression and coercion, by definition. Insofar as imposing normative judgments on (some of) those affected without their genuine consent and understanding is coercive, repressive, or both and it often is - doing so is indeed incompatible with Habermasian argumentation. But other conceptions of what might plausibly qualify as argument not only do not stipulate the inadmissibility of coercion and repression, but would in fact license some forms of these activities as inherently part of the process of argument - manipulation by rhetoric, for example. Habermas might correct for this problem by surrendering the term argumentation. He could accept that there are other conceptions of that activity with equally valid claim to the term, conceptions that would not serve his purposes against the skeptic; he 
might then appropriate another term, such as practical discourse, and run his argument against the $U$-skeptic accordingly. There are two snags in this strategy, though. One, the more rarefied the term Habermas appropriates, the more it suggests that the activity in question is rather specialized and, hence, that the opponent of $U$ can oppose without engaging in it - without, that is, engaging in an activity that requires her to presuppose $U$. Two, whatever the terms, Habermas's defense of $U$ tends toward question begging. The question at hand is, must we have everybody's genuine consent to and agreement upon normative judgments? If Habermas stipulates that the only practice or activity that could vindicate a negative answer to this question must itself meet its conditions, he clearly begs the question. In an effort to avoid this problem, Habermas argues that he is not making any stipulations here: he is simply noting a fact about what he calls the logic of argumentation or discourse - a fact that just exists, that is not capable of some sort of "ultimate justification."61 But this argument merely returns us to the quagmire of trying to ascertain that Habermas's understanding of argumentation or practical discourse holds up. Note that Habermas cannot resort to an outright normative claim here, such as the claim that we must (morally) have everybody's consent, because then he definitely cannot catch the skeptic.

Regardless of whether Habermas can defend $U$ to the thoroughgoing skeptic, $U$ has other problems as a constitutive criterion of objectivity. $U$ requires unanimous acceptance, under conditions of argumentation. This seems to be a way of guaranteeing standpointindependence. But, even if the ground rules for argumentation are in place, argumentation might not produce standpoint-independent judgments. Just because everybody is allowed to speak and to question does not mean that everybody will. Even when everybody does speak, differences in style and status will afford some yoices more weight. Furthermore, even if no speaker is silenced, all contributions receive equal consideration, and convergence results, the judgment reached still may not be objective, despite its standpoint-independence. Objectivity, even on the moral-rationalist conception, requires more. Objectivity also requires that reasons support the judgment, and convergence at the end of a process of argumentation need not be convergence based on reasons. Imagine a group in which people did nothing in support or criticism of a judgment but express their individual desires. The group reaches consensus on the basis of which desires are expressed most lustily, most prevalently, or both. Depending on the

61. Id. at 94-98. 
nature of the judgment, we may not think individual desires count as reasons for it. For the desire-driven group, convergence after argumentation may not signal objectivity. The same could be said about judgments based entirely on expressions of attitude or need.

Finally, and most seriously, Habermas's constitutive criterion of objectivity is wildly unrealistic. It puts any serious degree of objectivity out of reach. According to Habermas, $U$ sets the major condition a judgment must meet to qualify for objectivity: everybody affected by the judgment must be able to accept the anticipated consequences of its general observance. Given this condition, one might think that Habermas would accept some sort of hypothetical or counterfactual test for determining whether a judgment satisfies $U$, whereby an individual or a group of individuals goes through a thought experiment to see whether all affected would, if they were consulted, "be able to" accept the judgment in question. This alternative resembles the method Rawls advocates in $A$ Theory of Justice, in which he asks each reader individually to construct the original position and then conduct the deliberations that would take place there. ${ }^{62}$ Habermas, however, explicitly rejects this kind of hypothetical or counterfactual proceduralism. He says that "the justification of norms and commands requires that a real discourse be carried out and thus cannot occur in a strictly monological form, i.e., in the form of a hypothetical process of argumentation occurring in the individual mind."63 $\mathrm{He}$ also makes it clear that not only does full objectivity elude any judgment tested "monologically," but that, in his view, $U$ "suggests the perspective of real-life argumentation, in which all affected are admitted as participants." 64 When Habermas says that all affected must be able to accept the consequences of a judgment if that judgment is to qualify as objective, he really means that all affected must accept the consequences of the judgment. This comes as no surprise when one remembers the rules of discourse he claims $U$ presupposes. ${ }^{65}$ These stress the actual participation of every speaker-actor affected. Although Habermas does not state this explicitly, it seems quite clear that in his view for a judgment to achieve genuine objectivity, all those affected must participate in argumentation regarding it, and all participants must consent to it.

The problem is that this seems to make any serious degree of objectivity unattainable. Some of our most important judgments - be they

62. RAWLS, supra note 57 , at 17-22.

63. HABERMAS, supra note 36 , at 68 .

64. Id. at 66.

65. See supra text accompanying note 60 . 
purer normative ones or blend judgments - affect so many people that it is hard to conceive of a discursive procedure that could include all of them when a particular judgment's objectivity has been called into question. Even if technology could enable discussion on a far wider scale than we have managed to date, the costs of such discussion, in terms of time alone, are daunting. Additionally, the prospect of such discussion resulting in consensus - even in very near consensus - is minimal. Moreover, even if we thought this alternative to be worth the costs and even if consensus were obtained, massively widescale discourse still would not meet Habermas's conditions. Given that legal and political judgments will affect people who do not yet exist, it is impossible to obtain the consent of all those affected by these judgments.

Habermas might well respond that, although the conditions he sets are for full objectivity, objectivity is, after all, a matter of degree. $\mathrm{He}$ might regard his specification as a regulative ideal, to be approximated in practice. I too think that objectivity comes in degrees, ${ }^{66}$ but Habermas's regulative ideal is excessively ambitious. Our efforts to conform to an overly ambitious ideal are likely to be clumsy and dissatisfying. Habermas's scheme illustrates the problem well. Assume for the moment that Habermas has provided an attractive regulative ideal of objectivity. Even if this were so, it is impossible to say, with any degree of conviction, which practically feasible approximation of practical discourse is likely to preserve best this procedure's efficacy in guaranteeing objectivity. Acknowledging pragmatic constraints does not tell us just how to modify practical discourse so as to afford it appropriate regulatory force. For instance, if we are not going to include all affected, by what principle should we choose whom to include to get a successful approximation of impartiality? Representatives of each group affected? If so, how do we decide which members are representative for these purposes? Or should we eliminate those groups most likely to have a distorting influence if they are included at the expense of other groups? Moreover, who finally gets to decide which approximation we will use and how it will be implemented? If we manage to appoint a group of deliberators, we still need to handle the matter of consensus. Anybody who has ever engaged in group deliberations knows how hard uncoerced consensus is to achieve. When approximating practical discourse, should we settle for less than complete consensus? If so, what should the rule be? Something simple, like a two-thirds majority suffices to establish the objec-

66. See infra note 78 and accompanying text. 
tivity of a judgment? Or something more nuanced, which takes account of who happens to be consenting and who happens to be dissenting? Neither of these alternatives seem satisfactory. Maybe we should continue to rely on having complete consensus but weaken the prohibition on coercion. Maybe we should allow some forms of coercion on the ground that they do not undermine too much the objectivity of the ultimate judgment. We might allow people to display the kind of impatience that silences others into agreement, for instance. But it is hard to see how this would not be a threat to the kind of objectivity indicated by Habermasian practical discourse.

My point is not that a conception of objectivity suitable for blend concepts - or any other conception of objectivity, for that matter cannot or should not be responsive to pragmatic considerations. $\mathrm{My}$ point is that it must be responsive to them. Premising such a conception on an excessively ambitious regulative ideal, however, detracts from the effort. By designing a conception for conditions that cannot ever practically be met, one simply creates complex problems about how to adapt the account to the conditions in which we are. It would be much better to design our conception on the basis of our actual circumstances.

One way to remedy much of the impracticality of Habermas's dialogical moral-rationalist conception would be to eliminate dialogue as a prerequisite to objectivity. Monological moral-rationalist conceptions of objectivity, such as John Rawls's, do just this. ${ }^{67}$ Rawls advances the following conception of the objectivity of moral-political judgments.

Political convictions (which are also, of course, moral convictions) are objective - actually founded on an order of reasons - if reasonable and rational persons, who are sufficiently intelligent and conscientious in exercising their powers of practical reason, and whose reasoning exhibits none of the familiar defects of reasoning, would eventually endorse those convictions, or significantly narrow their differences about them, provided that these persons know the relevant facts and have sufficiently surveyed the grounds that bear on the matter under conditions favorable to due reflection. . . . To say that a political conviction is objective is to say that there are reasons, specified by a reasonable and mutually recog-

67. Rawls proffers an articulation of the concept of objectivity, along with three possible conceptions. RAWLS, supra note 56, at 110-21. In addition to the political-constructivist conception Rawls favors, he discusses a rational-intuition conception and a Kantian-moral constructivist conception. Here I will concentrate upon Rawls's preferred conception, the politicalconstructivist one. I do not adopt Rawls's articulation of the concept of objectivity because it is, in my opinion, overly baroque. Rawls delineates five "essential elements of a conception of objectivity," each of which is quite complex. Id. at 110-15. I prefer my own more simple articulation, see supra text accompanying note 47 , according to which the objective is that which possesses interpersonal validity in virtue of the reasons in its favor. 
nizable political conception, sufficient to convince all reasonable persons that it is reasonable. 68

The Rawlsian conception of objectivity differs from the Habermasian one in a number of respects. First and foremost, it is monological rather than dialogical. On the Rawlsian conception, a moral-political judgment need not go through any dialogical process, such as Habermasian argumentation, for it to be objective. A single individual's judgment, formed in total isolation from others, could be objective, if others would (largely) agree with it. This brings us to the second difference. The Rawlsian conception requires only hypothetical agreement rather than actual agreement. So a judgment can be objective even if others have not even considered it, let alone whether they already agree to it. Finally, the third difference between the Rawlsian and Habermasian conceptions lies in the scope of the people who must actually, or would have to, agree to a judgment for it to be objective. Whereas Habermas insists that agreement come from all those affected by the judgment, Rawls insists only that it come from those "reasonable and rational persons, who are sufficiently intelligent and conscientious in exercising their powers of practical reason, and whose reasoning exhibits none of the familiar defects of reasoning"69 - clearly, a subset of all those affected by most political judgments.

Each of the forgoing differences makes Rawls's monological moral-rationalist conception of objectivity more practical than Habermas's dialogical conception. Monological application is easier to execute than dialogical application; hypothetical agreement is easier to achieve than actual agreement; agreement with "reasonable," intelligent, conscientious, correctly reasoning people tends to come easier than agreement with "unreasonable," stupid, careless, or error-prone reasoners. ${ }^{70}$ Unfortunately, each of the differences between Habermas's conception and his own also detracts from the attractiveness of Rawls's conception as model for blend objectivity.

For a blend judgment to exert interpersonal validity - for an applied blend concept to exert reason-givingness interpersonally - it should live up to its social nature. ${ }^{71}$ It should be world-guided by the appropriate social facts, it should reflect the intersubjective evaluations of merit implicit in the taxonomy of worth to which the blend concept belongs, and it should, as purported, respond to communally endorsed

68. RAWLS, supra note 56, at 119 (footnote omitted).

69. Id.

70. Precisely what makes people "reasonable" or "unreasonable" is not entirely clear in Political Liberalism. Settling the question is not, however, important to my present purposes.

71. For my defense of this claim, see infra text accompanying notes 74-77. 
needs and interests. In controversial or novel cases, monological application is unlikely to accomplish any of this. First, no single individual is likely to be aware of and sensitive to all the relevant conventional mores, cultural ideas, community values, and customs that world-guide a particular blend concept. Users of the concept are likely to vary in their knowledge of and sensitivity to such information, depending upon how they are situated within the culture. Second, when a single individual applies a blend concept, the application may well reflect personal preference, rather than an intersubjective evaluation of merit, and represent a response to personal needs and interests, rather than communally endorsed ones. In a controversial or novel case, it is improbable - although not impossible - that a single individual would have the cultural information and insight necessary to apply a blend concept so that it lives up to its social nature. Dialogical application, on the other hand, stands a better chance of achieving this goal, thereby yielding blend judgments with interpersonal validity.

A dialogue that produces at least some degree of actual agreement among those who may or may not be "reasonable," intelligent, conscientious, and correctly reasoning, but who will be affected by the judgment, is likely to do a better job of keeping blend judgments true to their social nature than a dialogue that produces a judgment only hypothetically agreed upon by those with carefully circumscribed qualifications. Actual agreement among very different members of the culture keeps the judgment reflective of genuinely intersubjective evaluations of merit and responsive to communally endorsed needs and interests. Hypothetical agreement is all too easily presumed to exist and to extend to those who are quite different from one another.

A defender of the Rawlsian conception might respond that, while it takes actual agreement to determine if a judgment is in fact objective, actual agreement is not what makes the judgment objective. Likewise, such a defender might acknowledge that a dialogical procedure is useful for checking whether or not actual agreement obtains, yet it is not the use of such a procedure that makes the resulting judgment objective. I reject these defenses of the Rawlsian conception as a model for blend objectivity because I believe that a conception of objectivity should tell us not only what makes a judgment objective, but also something serious about what it takes for a judgment to be objective. Even conceding the distinction between criteria for objectivity and techniques for ascertaining whether the criteria have been fulfilled, we need a conception of objectivity that instructs us as to the latter as well as to the former. Insofar as the Rawlsian monological 
moral-rationalist conception does not, it suffers from a defect similar to the Habermasian conception: it presents us with an ideal without telling us how to instantiate it. This undermines the practicality the Rawlsian alternative seemed to offer.

In any event, with regard to blend judgments, the distinction between criteria for objectivity and techniques for ascertaining whether the criteria have been fulfilled is problematic. Recall that, for a blend judgment to exert interpersonal validity, it must apply the blend concept it contains so that it lives up to its social nature. This requires that the application reflect the appropriate intersubjective evaluations of merit and respond to communally endorsed needs and interests. Quite commonly, however, the evaluations of merit and needs and interests addressed by a particular blend concept are tacit and unspecified among the users of that concept. Under these circumstances, satisfying the major criterion for interpersonal validity - having the application live up to the blend concept's social nature - will require a technique that generates or reinforces an intersubjective evaluation of merit and a communal endorsement of the underlying needs and interests. At this point, it becomes difficult to distinguish sharply between criteria for objectivity in blend judgments and techniques for ascertaining whether the criteria have been fulfilled because the process of ascertaining fulfillment generates, at least partially, some of the criteria. This point emerges more clearly if we return to the question of whether it is possible for a single individual monologically applying a blend concept to arrive at an objective blend judgment, or whether this is simply impossible. In cases in which there is serious unclearness about which evaluations of merit are intersubjective or which needs and interests are communally endorsed, or both, dialogue may be the only technique that can effectively resolve these matters. If this is true, in those cases it is not only improbable that an individual applying a blend concept monologically will arrive at an objective blend judgment, it is impossible. Again, in such cases, it becomes difficult to distinguish sharply between criteria for objectivity in blend judgments and techniques for ascertaining whether the criteria have been fulfilled because the process of ascertaining fulfillment at least partially generates some of the criteria.

In the end, one might think a conception of objectivity should inform us not only about criteria for objectivity, but that it should also tell us something serious about which techniques would be best for ascertaining that these have been fulfilled, and that the distinction makes sense in the context of blend judgments. Or one might conclude that engaging in techniques to ascertain a judgment's objectivity 
generates, at least partially, prerequisites to that judgment's objectivity. In either case, Rawls's version of a monological moral-rationalist conception is inadequate as a conception of objectivity suitable to blend judgments.

\section{B. The Blend Conception of Objectivity}

So far, in discussing both scientific and moral-rationalist conceptions of objectivity, I have chronicled their shortcomings as conceptions of objectivity suitable for blend judgments. ${ }^{72}$ Yet the forgoing discussion yields affirmative information as well as negative. This is not surprising. All plausible conceptions of objectivity instantiate the same concept, in which the objective is that which possesses interpersonal validity by virtue of the reasons in its favor. Conceptions suitable for different kinds of judgments vary, depending upon the context in which the judgments in question are made and why objectivity matters in that context. Up to this point, I have emphasized differences in context and in why objectivity matters, but, to the extent that there are similarities in these respects, we can borrow from alternative conceptions of objectivity in articulating one suitable for blend judgments.

At the most general level, from the scientific and the moral-rationalist conceptions we learn about the structure of plausible conceptions of objectivity: they all account for the interpersonal validity of objective judgments in light of an important goal or interest shared by those party to the judgment. For scientific judgments, the goal is prediction and control of natural phenomena. For moral and political judgments, the goal is - again, on some leading accounts - coordination of action in mutually acceptable ways, without resort to force or violence. For blend judgments, specifying a single major goal is more tricky. As noted before, ${ }^{73}$ we make blend judgments in a wide variety of contexts, such as law, etiquette, humor, and aesthetics. Different goals inform different contexts. In fact, even within a single context, such as law, different goals inform different subcontexts. ${ }^{74}$ Whatever the more specific goal apropos a particular context, however, sincerely made blend judgments are always meant to be reason-giving. In order to exert the interpersonal validity constitutive of objectivity, objective blend judgments must be interpersonally reason-giving. They stand a chance of this because of the social nature of blend concepts. To capi-

72. I have also avoided taking a stand as to their merits as conceptions of objectivity for scientific and moral judgments, as the case may be.

73. See generally supra section I.B.

74. See my comparison of judgments of negligence and judgments of what is speech, infra notes $80-93$. 
talize on this chance, a blend judgment must apply its blend concept so that it lives up to this nature, which requires that the application be world-guided by the appropriate social facts, that it reflect the intersubjective evaluations of merit implicit in the taxonomy of worth to which the blend concept belongs, and that it respond, as purported, to communally endorsed needs and interests. The second and third of these requirements dictate that the blend conception of objectivity conform to the structure of scientific and moral-rationalist conceptions. A prerequisite to objectivity in blend judgment is that there be some shared goals, values, and interests.

Another lesson learned from the scientific and moral-rationalist conceptions of objectivity is that objective judgments, on whatever conception, are constrained judgments. Constraints upon judgment can take different forms. On the scientific-ontological conception, the natural world as it is - independent of scientists' beliefs, goals, desires, or representations of the facts - constrains which judgments count as objective. Only those that correspond to the world as it is qualify. On the scientific-methodological and the dialogical moralrationalist conceptions, procedures supply constraint. Only judgments that survive certain processes can count as objective. The method may be individualist (as in the individualist scientific-methodological conception), collective (as in the socialist scientific-methodological conception), dialogical (as in the dialogical moral-rationalist conception), or hypothetical (as in the monological moral-rationalist conception). Constraint guards against arbitrariness, whimsy, and idiosyncrasy; it ensures that not just any old judgment qualifies as objective.

Which form constraint should take within a given conception of objectivity depends upon why objectivity matters in the context in question and what kinds of reasons can sustain interpersonal validity there. Proponents of different versions of scientific conceptions disagree over what kinds of reasons can sustain interpersonal validity in the scientific contexts. Likewise, proponents of different versions of moral-rationalist conceptions disagree over what kinds of reasons can sustain interpersonal validity in moral and political contexts. Thus, proponents of rival versions of these conceptions of objectivity disagree over what form constraints upon judgment should take.

To sustain a blend judgment's interpersonal validity, reasons on its behalf must bear out the applied blend concept's social nature. Two types of constraint seem well suited to this task: dialogical methodology for arriving at blend judgments and empirical constraints upon 
blend judgments. As I argued previously, ${ }^{75}$ dialogical methods for making a blend judgment ensure that the applied blend concept lives up to its social nature and thus constrain which judgments will count as objective: some applications of a blend concept will not survive dialogical consideration. Empirical constraint of a certain kind also serves to ensure that an applied blend concept lives up to its social nature. In scientific conceptions of objectivity, empirical constraint takes the form of responsiveness to natural facts - either facts about the world as it is or facts about empirical appearances. In a blend conception of objectivity, empirical constraint comes in the form of responsiveness to the social facts that tend to world-guide blend concepts. Requiring this responsiveness to empirically ascertainable social facts constrains the possible applications of a blend concept.

According to both scientific-methodological and moral-rationalist conceptions, the reasons that sustain objective judgments are interpersonally available reasons. ${ }^{76}$ On scientific-methodological conceptions, the reasons in favor of an objective judgment are interpersonally testable and interpersonally comprehensible. Judgments that rely solely on individual personal preferences, tastes, and inclinations are insufficiently public to qualify as objective. Moral-rationalist conceptions distinguish interpersonally available reasons from expressions of individual personal preference, taste, and inclination, rejecting the personal in favor of the interpersonal, as bases for objective judgments. Even the Habermasian moral-rationalist conception - which authorizes participants in argumentation to assert and express their individual desires, attitudes, and needs - would not count these as bases of objective judgment unless a judgment premised upon them received collective endorsement.

Interpersonal availability of the reasons on behalf of a blend judgment contributes directly to its interpersonal validity. The kind of interpersonal validity that matters for blend judgments is interpersonal reason-givingness, which is far more sustainable when the reasons in favor of a particular application of a blend concept are interpersonally available, and when it is clear that these amount to more than expressions of individual personal preference, taste, and inclination. ${ }^{77}$

75. See supra text accompanying note 71 .

76. Due to its epistemologically externalist slant, the scientific-ontological conception of objectivity does not require interpersonal availability of the reasons that sustain a scientific judgment's interpersonal validity. This is because the scientific-ontological conception does not require that the reasons that sustain the judgment's interpersonal validity be available.

77. Cass Sunstein notes that, historically speaking, American constitutional law has required "government to provide reasons that can be intelligible to different people operating from different premises," as a means of ensuring impartiality. CASS R. SUNSTEIN, THE PARTIAL CONSTITUTION 24 (1993). Sunstein is not concerned with the objectivity of blend judgments, but he 
On all versions of the scientific and moral-rationalist conceptions of objectivity, convergence upon a judgment is a mark of its objectivity. On the scientific-ontological conception, convergence is a sign of responsiveness to the world as it is, independent of beliefs, goals, desires, or representations of the facts; on the scientific-methodological conception, convergence demonstrates that public testing has vetted a judgment for too much responsiveness to any individual scientist's personal inclinations, values, and beliefs. The dialogical moral-rationalist conception regards convergence as constitutive of objectivity; the monological moral-rational conception treats potential, if not actual, convergence in the same way. The connection between convergence and interpersonal validity is fairly obvious: if a person endorses a judgment, she considers it valid; if everybody endorses that judgment, they all regard it as valid. If the judgment applies a blend concept which, as such, has a social nature - the judgment will be interpersonally valid in a strong sense. That is, it will be interpersonally reason-giving, and those who have converged upon it will regard it as reason-giving for one another, as well as for themselves.

Convergence simply suggests - rather than vouchsafes - objectivity. Only when a convergence rests upon reasons is it a sign of genuine objectivity. Furthermore, convergence upon a blend judgment signals objectivity only when genuinely shared goals, values, and interests inform the dialogical method by which the judgment was reached, and when that method is genuinely dialogical. Without confidence in these matters, we cannot be sure that a converged-upon blend judgment has indeed applied a blend concept so that it lives up to its social nature. Disparities in power comprise one major obstacle both to the responsiveness to genuinely shared goals, values, and interests and to the unfolding of a genuinely dialogical method. Generally speaking, the greater the disparity in power between parties to a blend judgment, the more likely the judgment responds to goals, values, and interests shared only by the relatively empowered, and the more likely that their contributions control the dialogue through which the parties reach the judgment. A conception of objectivity suitable for blend judgments requires regulation of power disparities, which interfere with satisfying the other specifications for objectivity.

On the basis of a consideration of the merits and demerits of scientific and moral-rationalist conceptions of objectivity as models, we have arrived at a conception of objectivity suitable for blend judg-

emphasizes the relationship between interpersonally available reasons and impartiality in constitutional law for much the same reasons that I include support by interpersonally available reasons as one of the specifications for objectivity in blend judgments. 
ments. We have seen how each specification of this conception answers to the concept of objectivity: how each specification contributes to the interpersonal validity, sustained by reasons, of blend judgments in light of the social nature of the concepts they apply. The specifications, in sum, are: shared values, interests, and goals; constraints upon judgment in the form of dialogical methodology and empirical constraints; interpersonally available reasons; convergence; and regulation of power disparities. A blend judgment is very likely to be objective, then, when it meets these specifications.

\section{The Blend Conception as Regulative Ideal}

Having a conception of objectivity suitable for blend judgments does not guarantee that any blend judgments can satisfy it. In fact, blend concepts have certain definitive traits that might appear to rule out the possibility of objectivity in applying such concepts. First, the application of a blend concept is neither algorithmic nor wholly determinate. This means that there are genuinely close calls in application. In new or controversial situations it may be equally appropriate or inappropriate to apply a particular blend concept. One might think that, in such a situation, an objective application is out of the question, that the choice will come down to individual personal preference, desire, or inclination. Second, the interventionist stance is appropriate for making blend judgments. When deciding whether to apply a particular blend concept, especially in new or controversial situations, it is proper to take into account both the effects of applying or not applying the blend concept and whether we want these effects. It may appear that interventionist stance licenses the inevitable reliance on individual preference, desire, or inclination in deciding close cases. Third, appropriate application of a blend concept is conventional, in that appropriateness of application in new or controversial cases turns on whether the usual users of the concept accept it. Once more, this might suggest that blend judgments come down to particular individuals' personal preferences, desires, or inclinations.

Each of the aforementioned traits raises the same potential roadblock to objectivity in blend judgment. Whether the roadblock can be forestalled is a question that cannot be answered a priori. We need to examine specific blend concepts and the judgments that apply them to see whether they manage to avoid or surmount the obstacle posed by intrusion of individual personal preference, taste, or inclination. Each of the specifications included in the blend conception of objectivity addresses this problem. Now we need to see whether there are any blend judgments that meet the specifications, and what aids or impedes them 
in doing so. The blend conception of objectivity provides a regulative ideal for assessing the objectivity of blend judgments. ${ }^{78}$

I will take for an example the blend legal concept negligence and take us through a check for the objectivity of judgments of negligence. This will involve a review of some familiar features of common law method and apparatus, not because these features are little known, but to highlight the ways they contribute to or detract from the objectivity of judgments of negligence.

The legal system uses a complex methodology to make judgments of negligence. A quick summary: The trial - the setting of the initial, specific judgment of negligence - operates according to extensive rules of procedure and evidence. Specific judgments, as well as the trial court's application of the rules of procedure and evidence, are subject to appellate review. At both the trial and appellate stages, judgments and procedural and evidentiary rulings are all informed by accepted textual authorities, such as precedent and the Restatement of Torts. ${ }^{79}$ Throughout the process, the methodology relies on a sophisticated division of labor. The attorneys for the parties to the case must present evidence and claims according to the rules. The trial judge must oversee this process and decide whether the case is close enough to present to the jury. She must also instruct the jury in how to apply the law of negligence to the evidence, claims, and arguments presented by the attorneys. The jury must attend to the evidence, claims, and arguments presented and to the instructions given by the judge. It must then deliberate and apply the law to the specific facts of the case at hand. The appellate court must review all of the trial judge's decisions and decide whether the trial was satisfactory. Because this entire methodology is used repeatedly, the trial court judge has the additional task of attending to the appellate court's decisions to learn how to play her part; the appellate court must provide this type of instruction. With this apparatus fresh in our minds, we can turn now to whether and how it implements the specifications for objectivity in blend judgment.

\section{Shared Values, Interests, and Goals}

The evaluative points of negligence express the shared goals, values, and interests in the background of judgments of negligence. This

78. Using the blend conception of objectivity to measure the objectivity of blend judgments will bear out the claim that the blend conception is a less ambitious regulative ideal than the Habermasian moral-rationalist conception - sufficiently less that it is not prey to the objections I lodged against the latter on grounds of its overambition.

79. ReStatement (SECOND) OF TORTS $\S \S 281-503$ (1965). 
prerequisite is met to the extent that shared views obtain within society regarding the importance of allocating blame, deterring unacceptable risktaking, delineating what constitutes unacceptably dangerous behavior, serving corrective justice, and achieving judicial-administrative efficiency when settling disputes in which one person harms another and the parties are not in a contractual relationship. Laypeople, lawyers, judges, and legal scholars of all stripes regard each of these as important, worthwhile goals. There is, however, disagreement over the specifics of the relative importance of each of these points and about just what each one amounts to. For example, both among legal scholars and within the community, people disagree over whether deterring carelessness or achieving corrective justice more fundamentally informs negligence, or whether the latter is anything different from the former. ${ }^{80}$ Other examples: popular-moral intuition varies as to what corrective justice involves, ${ }^{81}$ and people disagree about how to define unreasonably dangerous risk. These sorts of disagreements preclude a complete sharing of the values, interests, and goals reflected in the evaluative points of negligence. To that extent, the objectivity of judgments of negligence is curtailed. But these disagreements are "internal" debates, set against a background of agreement as to the range and type of goals importantly served by judgments of negligence. To this extent, the specification of shared values, interests, and goals is met, and judgments of negligence enjoy, in this respect, a significant degree of objectivity.

\section{Constraints upon Judgment}

The complex methodology of common law adjudication institutionalizes a slew of constraints upon judgments of negligence. Some are a product of the common law's dialogical methodology, others a result of empirical constraints upon application of negligence, others more general byproducts of the common law system. I will consider these more general constraints first.

The mechanisms of summary judgment, directed verdict, and judgment notwithstanding the verdict bound the jury verdict. These mechanisms - and, if they do not apply, the jury verdict itself - are

80. Compare Richard A. Posner, A Theory of Negligence, 1 J. LEgal. Stud. 29 (1972) with George P. Fletcher, Fairness and Utility in Tort Theory, 85 HARV. L. REv. 537 (1972) and Ernest J. Weinrib, Toward a Moral Theory of Negligence Law, 2 LAw \& PHIL. 37 (1983).

81. There is long-standing disagreement as to whether negligence or strict liability better serves the end of corrective justice. For judicial discussion of this issue, see Hammontree $v$. Jenner, $20 \mathrm{Cal}$. App. 3d 528 (1971). For scholarly debate, compare Richard A. Epstein, A Theory of Strict Liability, 2 J. LEGAL STUD. 151 (1973) with Ernest J. Weinrib, Causation and Wrongdoing, 63 CHI.-KENT L. REV. 407 (1987). 
constrained by the evidence and the substantive law of negligence, about which the jury receives formal instruction from the trial judge. Established doctrine, in the form of previous appellate opinion, constrains the trial court, as does the prospect of potential appellate review of the pending case. In turn, precedent and the Restatement constrain appellate review.

So far, the constraints I have canvased are constraints internal to the legal system. They constrain legal and lay actors. A second set of constraints has a basis external to the legal system. These constraints owe to the relationship between the legal system and the larger society. Negligence, a legal concept applied by lay people (jurors) and according to which the laypeople are supposed to act, must be intelligible to and resonate with laypeople. This means that the concept cannot become excessively esoteric or technical, and this fact constrains the concept's doctrinal development. In fact, the legal concept negligence, along with its subsidiary concepts of reasonable person and unreasonable risk, has apparently been engineered out of vaguer social concepts of negligence and unreasonableness. The legal doctrine of negligence embeds the connection between the legal and social concepts. The reasonable person is a composite of the community, albeit an idealized one; unreasonable risk is largely a matter of popular valuation. Thus, while legal mechanisms constrain jury judgments of negligence, social facts about reasonable behavior and risk constrain legal development of negligence and its subsidiary concepts.

Current pressures on the common law system undermine the power of the forgoing constraints upon judgments of negligence. As the amount and complexity of litigation overwhelm judicial resources, judicial constraints suffer: trial judges increasingly promote settlement, removing both community constraint represented by a jury verdict and the trial court constraint represented by checks for summary judgment, directed verdict, and judgment notwithstanding the verdict; fewer cases reach appellate courts because even defendants whose conduct was incorrectly labeled negligent pay damages rather than finance a lengthy appeal. Even more specifically, legal constraint upon the jury's application of negligence suffers from jurors' inability to comprehend the trial judge's instructions to them. ${ }^{82}$ Despite the pres-

82. This difficulty has been documented by Robert P. Charrow \& Veda R. Charrow, Making Legal Language Understandable: A Psycholinguistic Study of Jury Instructions, 79 ColuM. L. REV. 1306 (1979); see also AMIRAM ElWORK ET AL., MAKING JURY INSTRUCTIONS UNDERstandable 3-24 (1982); Phoebe C. Ellsworth, Are Twelve Heads Better than One?, LAw \& CONTEMP. ProBs., Autumn 1989, at 205, 218-24.

Sometimes, of course, juries choose to ignore even well-understood judicial instructions in favor of their own sense of fairness. If this practice is not widespread, it may not constitute a threat to constraint - quite the opposite. Such jury nullification imposes a constraint on the 
sure these developments exert, though, they have not completely dismantled the apparatus of common law adjudication, which continues to impose a degree of constraint upon judgments of negligence.

\section{Constraints: Dialogical Methodology}

The methodology by which judgments of negligence are made institutionalizes a series of dialogues, many of which relate to one another. In other words, rather than all participants conversing with one another, each engages in one or more dialogues and witnesses several others. This produces a system of overlapping dialogues.

Even before the trial commences, dialogue between attorneys, future jurors, and the judge begins at voir dire. At trial, the plaintiff and the defendant engage in dialogue with one another, through their attorneys. All other participants witness this. The attorneys engage in dialogue with the trial court, much of which is witnessed by the parties and the jury. The trial court engages in dialogue with the jury, witnessed by the parties and their attorneys. The jurors engage in dialogue with one another. On appeal, the attorneys engage in dialogue with the appellate court. The members of the appellate court engage in dialogue with one another - another dialogue that goes, in large part, unwitnessed. The appellate court engages in dialogue with the trial court.

Finally, and more generally, a broader legal audience engages in dialogue with each other and with the courts, most often with appellate courts. Through means such as scholarly writing and the Restatement, legal scholars and select practitioners converse with one another. Much of this conversation addresses the courts directly and the rest indirectly.

All of these "dialogues" are formalized and resemble informal conversation only in broad outline. Nonetheless, each facilitates the exchange of ideas, arguments, information, and claims between all participants in the methodology of making judgments of negligence. For example, juries may never speak directly to judges or legal scholars, but they convey, to some extent, their ideas through the verdicts they reach. Similarly, trial judges do not sit down for a heart-to-heart with appellate courts, but trial courts inform appellate courts of their understanding of the law of negligence, evidence, and procedure

development of the law of negligence by signaling to courts the limits of popular-social tolerance for how negligence has been developed. Too frequent disregard of well-understood instructions would, however, cut sharply against the constraint attempted by judicial development of blend legal concepts, thereby cutting against the objectivity of blend legal judgments. 
through the rulings they make, the jury instructions they give, and the opinions they occasionally write.

A more serious impediment to meeting this specification arises from imperfect implementation of another specification: the regulation of power disparities. ${ }^{83}$ Socioeconomic factors such as wealth, status, gender, and race result in overrepresentation of empowered groups and their interests in each of the forgoing dialogues. For example, the practicing bar and the judiciary are largely white and male, and this affects their contributions to the dialogues in which they participate. ${ }^{84}$ Likewise, the effects of background socioeconomic factors affect dialogue in the jury room.

All jurors do not contribute equally to the discussion. In theory, every juror is supposed to have an equal say in the deliberation and verdict, but in practice there are vast differences in how much jurors talk. . . . Research studies show that the amount of group participation is related to the characteristics of the individuals themselves. Just as external status is reflected in the selection of the foreperson of the jury, it is reflected too in who participates the most during deliberation. On the average, men speak more than women .... Those with more education and higherstatus occupations also tend to dominate the discussion. Likewise, the foreperson, usually male, is regularly one of the most active participants. ${ }^{85}$

Sexism and snobbery hamper the injection of a Habermasian element - that is, free and unconstrained dialogue in the jury room - into dialogical common law methodology. Wealth influences that methodology from the outset of litigation, when financial resources affect potential and actual litigants' decisions to bring suit, settle, or appeal, whatever the merits of their cases; wealth also influences litigants' abilities to hire talented legal counsel.

There are some countervailing factors that correct for some of these problems. Contingency fee arrangements in personal injury cases, for instance, introduce some litigants to the dialogue who would not otherwise be able to afford to participate. Representation of women, white and nonwhite, and men of color in both the bar and the judiciary has been steadily increasing. Even when power disparities do interfere with the extensiveness and authenticity of dialogue, dialogue still takes place and can achieve significant range and genuineness.

83. For further discussion of that specification, see infra section II.B.7.

84. See David Millon, Objectivity and Democracy, 67 N.Y.U. L. REv. 1 (1992) (urging the importance of increasing racial, gender, and socioeconomic diversity within the legal profession for the sake of increasing objectivity); Girardeau A. Spann, Pure Politics, $88 \mathrm{MrCH}$. L. REv. 1971 (1990) (arguing that, because most members of the Supreme Court are white, the Court has trouble making countermajoritarian decisions).

85. VAlerie P. HANS \& Neil Vidmar, Judging the JuRy 108 (1986); see also Ellsworth, supra note 82 , at 213-14. 
When it does, it performs its function of constraining judgment and thereby bestows some degree of objectivity.

\section{Empirical Constraints}

Empirical constraint enters into the methodology for making judgments of negligence in two ways. First, the parties must present empirical, if not scientific, evidence of the events giving rise to the claim. Second, correct application of reasonable person and unreasonable risk requires attention to empirically ascertainable, if social, facts regarding matters such as typical degrees of caution in various circumstances and popular valuation of various activities. Of course, each of these empirical constraints operates imperfectly. Litigants do not always present their evidence systematically and coherently, and each side seeks to complicate the jury's understanding of the other's testimony; judges obtain some of their empirical information about social facts in a highly casual, and therefore potentially inaccurate, fashion. Nonetheless, empirical information does call for or rule out certain applications of negligence, lending judgments that apply the concept a degree of objectivity in this regard.

\section{Interpersonally Available Reasons}

The methodology for making judgments of negligence demands interpersonally available reasons on behalf of these judgments, as well as on behalf of the background guidelines for making them. Even judgments and guidelines perhaps initially proffered on the basis of individual personal preference, taste, or inclination are vetted through a process that generates interpersonally available supporting reasons. A naked expression of individual preference, taste, or inclination does not count as a judgment of negligence.

The jury's verdict or the trial judge's grant of summary judgment, directed verdict, or judgment notwithstanding the verdict is supposed to rest on the evidence presented. This evidence, like that required in science, must be interpersonally accessible. Even when the fact claimed is highly private - such as the fact of an individual's pain and suffering - the party claiming the fact must present evidence accessible to the jurors, such as first-person description or expert testimony on external signs of the fact. If the plaintiff cannot supply sufficient interpersonally accessible evidence on behalf of his claims, the trial judge must grant summary judgment for the defendant, thus giving the plaintiff powerful incentive to produce such evidence.

In the course of jury deliberations, jurors work to persuade one another of the verdict they favor. They use a variety of tactics, among 
them the advancement of interpersonally available reasons in support of their preferred verdict. Even if some jurors become persuaded on other grounds, the jury verdict should, in principle, have the support of such reasons. That is, regardless of the actual reasons on which the jury's verdict rests, if the verdict could not possibly be based on reasons interpersonally available to reasonable jurors, the trial court must grant a judgment notwithstanding the verdict predicated on the lack of such support.

Appellate opinions collect and relate interpersonally available reasons on behalf of the decisions they announce. They do not present the decisions as expressions of the personal tastes, preferences, and inclinations of the appellate judges. Instead, appellate opinions provide lower courts with reasons for the decision, thereby also providing reasons to support future trial court decisions.

The forgoing processes for ensuring that interpersonally available reasons underpin judgments of negligence work imperfectly, to be sure. The processes themselves are not always followed, as is evidenced by the increasing use of unpublished appellate opinions. ${ }^{86} \mathrm{De}-$ viations like this one undercut the impetus to generate interpersonal reasons for the guidelines for applying negligence. Even when interpersonal reasons are generated, limitations on the diversity of the participants in the processes cut against the interpersonality of the reasons in support of the resulting judgments. Still, as with the other specifications, although common law methodology may implement this one imperfectly, it does implement it and thereby achieves a measure of objectivity in judgments of negligence.

\section{Convergence}

Just as common law methodology institutionalizes its dialogical dimension in the form of overlapping dialogues, it incorporates convergence in a hierarchy of mutually supporting convergences. Rather than every participant in the methodology converging on each specific judgment of negligence or each doctrinal guideline, participants join in different convergences at different points in the methodology. These convergences reinforce one another.

The jury verdict represents the jurors' convergence upon a specific judgment of negligence. When the trial judge and the appellate court let a jury verdict stand, they reinforce the jurors' convergence. Likewise, a trial outcome that withstands appeal reflects convergence of

86. Cf. Lauren K. Robel, The Myth of the Disposable Opinion: Unpublished Opinions and Government Litigants in the United States Courts of Appeals, 87 MICH. L. REv. 940 (1989) (criticizing the use of unpublished opinions). 
the trial court and the appellate court upon the guidelines for making judgments of negligence. Judicial convergence is also manifested by a trial judge's reliance upon appellate precedent when deciding whether to take a case from the jury's hands or how to instruct the jury. Precedent represents appellate convergence on these issues. Finally, the Restatement and the courts' use of it reflect two other levels of convergence. The provisions of the Restatement embody convergence among courts, scholars, and practitioners. Judicial reliance on these provisions represents another convergence upon the principles they express, one that reinforces the prior convergence presented in the Restatement itself.

As I noted in my previous discussion of convergence as a mark of objectivity, convergence only suggests, not guarantees, objectivity. ${ }^{87}$ To the extent that a convergence seems to rest on something other than interpersonally available reasons, fails to reflect genuinely shared goals, values, and interests, or is not the product of genuine dialogue, it fails to vouchsafe objectivity. I have already indicated when and where we have reason to question whether a converged-upon judgment of negligence rests on interpersonally available reasons, whether it reflects genuinely shared goals, values, and interests, and whether it is the product of genuine dialogue. Our level of doubt about these matters is the measure of how much we should discount convergence as a mark of the objectivity of any particular judgment of negligence. Short of complete skepticism about them, however, convergence remains something of an indicator of a judgment's objectivity.

\section{Regulation of Power Disparities}

In discussing the previous specifications I have already canvased the failure of common law apparatus to regulate adequately power disparities due to background socioeconomic factors. Here, I turn to power disparities that the common law apparatus more successfully regulates. These are power disparities among the participants due to the different roles the apparatus assigns them. Although the apparatus allocates power to certain participants - lawyers, judges, and juries each have powers specific to their roles - it also regulates the effects of this allocation through a careful division of labor. For example, although courts and other legal specialists enjoy tremendous power by virtue of their control over doctrinal development of the concept negligence, this power is mitigated by the jury's direct command over specific judgments of negligence. In turn, legal mecha-

87. See supra text following note 77 . 
nisms - such as summary judgment, directed verdict, and judgment notwithstanding the verdict - mitigate the jury's power. These mechanisms, however, operate according to how reasonable juries can be expected to reach a verdict, thus reintroducing an element of community control over legal apparatus. Likewise, although trial courts enjoy great power over the actual trials of negligence causes of action, appellate power to review trial court behavior limits trial court power. In turn, the need for appellate courts to make their reasoning accessible and persuasive to lower courts curtails the appellate power of review.

In reviewing how common law apparatus implements the regulative ideal provided by the blend conception of objectivity and how judgments of negligence fare according to that ideal, we see that judgments of negligence enjoy some degree of objectivity, although they do not achieve anything like total objectivity. We also see the blend conception's regulative power in pinpointing which features of common law adjudication foster objectivity, and which impede it. To reinforce the point that judgments of negligence enjoy a significant degree of objectivity and to appreciate fully the regulative power of the blend conception of objectivity, it helps to see how another kind of legal judgment fares when we measure its objectivity against the blend conception.

Consider judgments of when, for First Amendment purposes, a form of expression is speech. Put briefly, my claims are: first, that speech, as it appears in the law of the First Amendment, is a blend concept - and therefore judgments of speech are blend legal judgments - and, second, that there are both methodological and societal obstacles to the objectivity of judgments of speech.

One of the judgments that must be made when deciding whether an activity merits First Amendment protection is whether the activity is speech. This question is almost exclusively a question of law, rather than fact. Courts, not juries, decide it. ${ }^{88}$ The textual basis for deciding the question consists of Supreme Court precedent - there is no Restatement or analog to a Restatement in the area of First Amendment law. 89

88. For discussion of the role of appellate courts in First Amendment adjudication, see Bose Corp. v. Consumers Union of U.S., Inc., 466 U.S. 485 (1984), in which the Court reiterates the principle that, in First Amendment cases, appellate courts have the authority and obligation to review and decide de novo issues of law and of fact, and even "mixed" issues of law and fact. 466 U.S. at 501.

89. There are influential treatises, written by single individuals. See, e.g., LAWRENCE TRIBE, AMERICAN CONSTITUTIONAL LAW $\S \S 12-1$ to -39 (2d ed. 1988). But, while Tribe's work may be steeped in prior convergences regarding constitutional law, a treatise like his reflects a single 
Speech itself is a closet blend concept. It is often taken to be much like water or proton: not a member of an evaluative taxonomy; lacking an evaluative point arising from human needs, interests, and desires; world-guided and not reason-giving; neither appropriately nor actually applied from an interventionist stance. None of these characterizations, however, is accurate. Speech clearly delineates one category in a classificatory scheme of worth. Its application bestows protection upon the activity in question, on grounds of the activity's worth to self-expression, or, if one takes a different view of the interests addressed by First Amendment doctrine's evaluative taxonomy, to the ongoing pursuit of the best ideas. Other categories in the taxonomy include commercial speech, fighting words, libel, and obscenity. Activities to which these concepts apply all receive, in varying degrees, less protection than activities to which speech applies. The evaluative points of the First Amendment taxonomy of worth include increasing knowledge, ensuring political liberty, and promoting self-expression. What happens when people disagree over whether speech applies evidences the reason-givingness of the concept: they debate whether state interference with the activity in question threatens the evaluative point(s) of the First Amendment taxonomy of worth. In other words, they do not simply look for further facts to settle the matter; they seek to answer a normative question. Once a novel question of application is decided, the concept's world-guidedness is altered; in this way speech's reason-givingness informs its world-guidedness. So, once the U.S. Supreme Court decided that labor picketing ${ }^{90}$ or wearing armbands 91 was speech, the concept's world-guidedness no longer required that an activity be verbal for it to qualify as speech. Courts commonly apply speech from an interventionist stance, which suggests that this stance is appropriate for its application. In deciding whether certain activities count as speech, courts consider whether we want to tolerate or encourage them. If so, this weighs in favor of applying the concept.

Thus, speech belongs to an evaluative taxonomy, informed by evaluative points; it is simultaneously world-guided and reason-giving, and its reason-givingness informs its world guidedness; and it is often and appropriately applied from an interventionist stance. Speech is, in short, a blend legal concept. But blend judgments of what is speech appear to many to be less objective than blend judgments of negli-

individual's (the author's) views to a greater degree than does a collectively compiled work like a Restatement.

90. Thornhill v. Alabama, 310 U.S. 88 (1940).

91. Tinker v. Des Moines Indep. Community Sch. Dist., 393 U.S. 503 (1969). 
gence. ${ }^{92}$ This appearance makes sense, according to the blend conception of objectivity: according to that conception, judgments of what is speech are less objective.

Judgments of speech are relatively unconstrained compared to judgments of negligence. Neither the lay community, through the jury, nor the broader legal community, through a Restatement, checks judicial development and application of speech. Likewise, jurors and legal specialists are largely absent from whatever convergences exist upon speech's application and development, reducing the overall levels of convergence. So too there are fewer dialogues, given the absence of jury deliberation and colloquy amongst specialists devising a Restatement; accordingly, fewer reasons on behalf of application and guidelines for application are generated. In the absence of these conditions or anything equivalent to them, the objectivity of judgments of speech is suspect. We have reason to doubt whether they are - or are seriously - interpersonally valid by virtue of the reasons in their favor.

Perhaps changes in methodology could eliminate or reduce each of the forgoing impediments to the objectivity of judgments of what is speech. A methodology revised to more reliably generate objectivity need not resemble common law methodology in all its particulars, but it should meet the specifications laid down by the blend conception of objectivity. Regardless, however, of how we might revise our method for making judgments of speech, a more intractable impediment to their objectivity lies in the way. In a pluralistic, heterogeneous society such as ours, people disagree sharply over the needs, interests, and desires that give rise to the evaluative points of the First Amendment taxonomy of worth. They also disagree sharply over the importance or strength of these needs, interests, and desires compared to rival ones. Many of these disagreements arise from large-scale political and structural conflicts. ${ }^{93}$ This means that the basic prerequisite to objectivity in blend judgment is far from met. A serious question emerges: with the prerequisite so unsatisfied, could anything like the full-blown common law methodology be used for judgments of what is speech?

92. Consider attacks upon the characterization of pornography as speech for First Amendment purposes. See, e.g., Andrea Dworkin, Against the Male Flood: Censorship, Pornography, and Equality, 8 HARv. WoMEN's L.J. 1, 8-9 (1985); Catharine A. MacKinnon, Pornography, Civil Rights, and Speech, 20 HARV. C.R.-C.L. L. REv. 1, 16-17, 50-52 (1985).

93. Consider, for example, the heated disagreement about government regulation of pornography. One take on the dispute suggests that feminists who favor regulation and ardent defenders of the First Amendment rights of pornographers - a group that includes some feminists disagree not only about what counts as speech and what the worth of speech is, but also perceive women's (and men's) interests and conditions very differently. Their disagreements on the latter issues indicate the kind of large-scale political and structural clashes that color the fiercest First Amendment battles. 
Could a more diverse array of participants have meaningful dialogue on the subject and could they converge regularly on particular decisions? On the other hand, without widespread participation in the process of developing and applying speech, arriving at relevant shared needs, interests, and desires becomes less likely. Common law methodology reinforces the conditions that satisfy the prerequisite to objectivity. With regard to judgments of what is speech, more refined questions to ask are whether there are sufficiently shared needs, interests, and desires for something like common law methodology to get off the ground, and whether, once off the ground, the methodology would foster further sharing of needs, interests, and desires.

We need not look to constitutional law for examples of blend judgments whose objectivity is more contentious than the objectivity of judgments of negligence. Consider judgments of rape. Rape is clearly a blend concept - but one about which there is deep dispute as to the needs and interests to which it responds. While some think rape responds only to women's interest in being safe from violently imposed sexual intercourse, ${ }^{94}$ others think it responds to women's interest in noncoercive sexual intercourse, including being free from nonviolent coercive intercourse. ${ }^{95}$ This depiction of the debate undoubtedly oversimplifies it. The point is that the very deep dispute over the needs and interests to which rape responds sharply limits the concept's capacity to figure in objective judgments. Judgments of rape are made absent a background of shared values, interests, and goals. This in itself curtails their capacity for objectivity. Furthermore, without such a background, there is fundamental disagreement about the meaning and relevance of the empirical information usually considered when judging rape. If she did not say "no," but she did not say "yes," what does this mean and how does it bear on the judgment? If he did not hit her but he got her stoned, what does this mean and how does it bear on the judgment? Questions like these are intractable in the face of deep division over the needs, interests, and values that inform rape. Without settling such questions, empirical information cannot constrain effectively the application of rape, casting another doubt on the objectivity of such judgments.

When we compare judgments of negligence, judgments of speech, and judgments of rape, we discover that the potential for objectivity varies between different types of blend legal judgments. It is, however,

94. Commonwealth v. Berkowitz, 609 A.2d 1338, 1346-48 (Pa. Super. Ct. 1992); KATIE RoIPhe, The Morning AfTer: SeX, FeAR, ANd Feminism on CAMpUS 51-84 (1993).

95. In re M.T.S., 609 A.2d 1266 (N.J. 1992); Lani A. Remick, Read Her Lips: An Argument for a Verbal Consent Standard in Rape, 141 U. PA. L. REv. 1103 (1993). 
unlikely that current limits upon potential objectivity are conceptual or a priori. Most ambitiously, we should work to reduce and ultimately to eliminate racism, sexism, and snobbery. This would facilitate the formation of shared goals, needs, and interests to undergird the objectivity of judgments of negligence, speech, and rape.

Less grandly - and, alas, more realistically - we could make methodological changes that would foster objectivity. For making judgments of speech, we could design a methodology that would include a wider array of participants. When it comes to judgments of negligence, we could fine tune common law methodology. For instance, we could revamp jury instructions, increasing their comprehensibility and thereby enhancing constraint upon jury verdicts. ${ }^{96}$ Or we could have the court appoint the foreperson of the jury, assigning the role to someone from a group whose members normally do not participate much in deliberation; alternatively, and less intrusively, we could instruct juries to select their forepersons randomly, so that the role would not fall disproportionately to well-off white men. We could concentrate upon increasing the ranks of nonwhite and (white and nonwhite) female appellate judges, thus enhancing the interpersonality of the reasons proffered by appellate courts on behalf of their decisions.

I could extend this list of recommendations, but my aim here is illustrative, not exhaustive. My sample recommendations show the critical power afforded by the blend conception of objectivity. That conception provides leverage with which to reshape how we make blend legal judgments and a vantage point from which to advance more sweeping socioeconomic revisions. In my view, this proves the advantages of developing a conception of objectivity suitable for blend judgments rather than trashing aspirations to objectivity - and the idea of objectivity itself - altogether.

The conception of objectivity that I have articulated functions as a regulative ideal, one with advantages over both the Habermasian and the Rawlsian moral-rationalist conceptions. Unlike the Habermasian moral-rationalist conception, which I criticized for its overambition, blend objectivity provides a pragmatic regulative ideal. Unlike those of the Habermasian conception, its specifications can be implemented in the real world because each of its specifications can be met substan-

96. Psycholinguists and lawyers have already drafted jury instructions on negligence that test juries have proven to understand better than traditional instructions. Charrow \& Charrow, supra note 82, at 1348-51. ELWORK ET AL., supra note 82, at 12-17, have demonstrated that jurors who received traditional Michigan jury instructions did no better at reaching correct verdicts than jurors who received no instructions at ail, whereas jurors who received instructions rewritten for better comprehension performed substantially better than the uninstructed group. 
tially without excessively wide participation or totally complete agreement. In contrast to the Rawlsian conception, ${ }^{97}$ the blend conception of objectivity is not a hypothetical criterion for objectivity, but a practically oriented heuristic. It directs us as to what we should do to achieve objectivity, rather than allowing each of us to rest content with the calculation that we probably have done so by satisfying a counterfactual test. Moreover, because the blend conception is neither monological nor does it limit participation to those who are "reasonable," instantiating its specifications is more likely to yield blend judgments guided by appropriate social facts and responsive to intersubjective evaluations of merit than would satisfying the Rawlsian criterion.

Whereas the Habermasian conception requires that all affected by a judgment participate in making it, freely and fully introducing any and all assertions and expressions of attitude, desire, and need, blend objectivity does not demand this sort of ideal speech situation, requiring instead only some kind of dialogical constraint upon judgment. Consider how common law methodology implements this specification. Common law methodology excludes the direct participation of any number of people affected by particular judgments of negligence. Unless called as witnesses, friends and family members of the parties do not participate in the trial; nor do those who will have to rethink and modify their behavior in light of the judgment; nor do appellate judges who may have to review the judgment. Even those who participate in the trial do not all participate in deliberation and decision of the verdict, the specific judgment of negligence; only jurors engage in that activity.

Despite these restrictions, however, common law methodology also displays respect for the importance of participation to objectivity through its dependence upon the indirect participation of a large number of people. The methodology relies heavily upon sources such as precedent and the Restatement, bodies of material that only develop through the participation of large numbers of people, over many years. In addition, in principle the methodology should provide many opportunities for all to participate directly, either as parties, jurors, lawyers, or judges. Yet, by limiting direct participation in particular judgments of negligence, common law methodology ensures that disputes will be adjudicated and specific judgments made.

Common law methodology restrains opportunity for assertion and expression according to role. The methodology assigns each partici- 
pant a role, and they may assert or express only role-appropriate claims at role-appropriate times. The parties and their attorneys may not say whatever they want at any given moment during a trial. By and large, attorneys speak on behalf of their clients, except when the client takes the stand. Attorneys speak during the periods allotted to them - even their opportunities to object repeatedly are governed by the trial judge. Although the judge regulates when others may or must speak, even she cannot permissibly say anything she wants during the course of a trial. Both implicit norms and explicit sanctions confine her to remarks suitable to her role as judge. If her remarks veer too wildly from role-appropriateness, the proceedings can even be declared a mistrial. Restraining expression and assertion has obvious practical advantage - trials must end. If every participant said everything, or even every relevant thing, that occurred to him, trials never would end. In addition, restricting speech according to role reinforces the division of labor built into legal methodology. This division of labor produces the layers of constraint upon judgments of negligence and regulates the effects of power disparities among the participants, so its maintenance is vital.

Layered constraints pragmatically answer to real-world imperatives. Although each of the participants in the methodology operates according to different constraints, all contributions operate according to some constraint. Lay participants are constrained by legal apparatus; attorneys are constrained by trial judges, who are, in turn, constrained by appellate courts; legal specialists of all kinds are constrained by the need for community access to legal doctrine. This system of interlocking constraint responds to the need to situate different participants differently within the methodology, thereby rendering different sorts of constraints appropriate for different actors.

In a similar move to practicality, rather than having all participants engage in dialogue with one another simultaneously - a disorderly, time-consuming prospect - common law methodology enacts a series of dialogues, most witnessed by participants not currently engaged. Jury deliberations go unwitnessed, making it possible for them to serve as a pragmatic stand-in for a Habermasian ideal speech situation. In the privacy of the jury room, jurors have relatively extensive freedom, compared to the other participants during the rest of the trial, to express and assert a wide range of views and claims. ${ }^{98}$ For six

98. The vast majority of jurisdictions have made it illegal to record jury deliberations, largely in response to social scientists who recorded, with the permission of the trial judge and parties' counsel, five civil cases in Kansas during the 1950s. The recording provoked a huge outcry among both lawyers and laypeople. HANS \& VIDMAR, supra note 85, at 99 . The public and legal 
or twelve people with a common task, relatively unrestrained assertion and expression is a workable enterprise.

As with layered constraints and serial dialogues, common law methodology implements the specification of convergence in a highly focused way. Rather than seek widespread convergence specifically on particular judgments of negligence, the methodology aims for smallscale convergence on particular judgments, backed by wide-scale convergence on the way in which juries should apply negligence. A jury verdict that withstands appellate review, with the review itself based upon long-standing precedent regarding application of negligence, represents this kind of backed convergence. Even an unappealed jury verdict presumptively enjoys wide-scale background backing. Insofar as the losing party's decision not to appeal rests on an accurate estimation that the judgment would survive appeal, the trial verdict conforms to converged-upon guidelines for the application of negligence.

Finally, consider how common law methodology specifies support by interpersonally available reasons. The mechanisms that generate interpersonally available reasons in support of judgments of negligence or guidelines for these judgments do not guarantee that these reasons are indeed the ones that persuaded the participants. Providing this kind of guarantee, however, is a highly unrealistic aspiration. It would take a kind of psychological insight hard to imagine possible. So, again, common law methodology adopts a pragmatic solution, requiring participants to generate or look to interpersonally available reasons, even if these reasons are not actually the basis of the participants' decisions. This means that there must be interpersonally available reasons supporting the decisions, even if these reasons are not the participants'. The methodology demands that participants generate interpersonally available reasons on behalf of their decisions: appellate courts must publish opinions articulating them; trial courts must think about them when deciding whether to grant summary judgment, directed verdict, or judgment notwithstanding the verdict; and jurors must persuade one another in collective deliberation. The decisions of each decisionmaking participant - jury, trial judge, appellate court receive review from another participant: the trial court reviews the jury's decisions; the appellate court reviews the trial court's; and the legal community as whole examines the appellate court's. Having to think of interpersonally available reasons on behalf of one's decisions and knowing that these decisions must survive the scrutiny of others

reactions attest to broad social support for the ideal of the juryroom as a locale for freewheeling, unconstrained debate and discussion. 
make it more likely that interpersonally available reasons will in fact form at least part of the basis for one's decisions.

Bounded participation, restrained expression and assertion, interlocking constraints, layered dialogues, articulated and articulable interpersonal reasons, small-scale convergence backed by wide-scale convergence: each of these features of the common law version of blend objectivity illustrates the way the blend conception answers to the demands of the real world, rather than to an obviously unattainable ideal. Common law methodology is only one possible instantiation of the blend conception of objectivity. Any instantiation should, however, capitalize on the blend conception's pragmatic orientation.

\section{What The Blend CONCEPTION OF OBJECTIVITy OfFeRs to LEGAL SCHOLARSHIP}

Thus far, I have been demonstrating the advantages of the blend conception of objectivity in formulating a practice for making these judgments. The blend conception of objectivity also enjoys advantages in the context of scholarly debates over objectivity in law. Most importantly, perhaps, the blend conception provides a vantage point from which to diagnose and understand a variety of disagreements over objectivity in law. The blend conception also supplies a source of leverage for penetrating criticism of certain classes of legal judgments precisely because it carefully delineates what objectivity requires in this context, rather than completely dismissing the possibility of objectivity, as certain critics do. Finally, the blend conception enables us to sidestep some issues that have sharply divided defenders and critics of law's objectivity, matters that the blend conception renders largely irrelevant.

Much of the debate over objectivity in law has focused on the objectivity of appellate judicial decisions. Both critics and defenders center on these. ${ }^{99}$ The focus of my inquiry, on the other hand, has

99. Critics who have concentrated on appellate judicial opinions include Felix Cohen, Duncan Kennedy, Gary Peller, and Mark Tushnet. See Cohen, supra note 12; Kennedy, supra note 5; Gary Peller, Neutral Principles in the 1950's, 21 U. MICH. J.L. REF. 561, 606-17 (1988); Mark V. Tushnet, Following the Rules Laid Down: A Critique of Interpretivism and Neutral Principles, 96 HaRv. L. Rev. 781 (1983). Ronald Dworkin, Stanley Fish, and Owen Fiss are among the defenders who have done the same. See DworkIN, EMPIRE, supra note 4; DworKIN, PRINCIPLe, supra note 4, at 119-77; STANLey Fish, Doing What Comes Naturally: Change, Rhetoric, and the Practice of Theory in LITERaRy and Legal Studies 1-33, 87-102, 120-40, 372-98 (1989); Owen M. Fiss, Conventionalism, 58 S. CAL. L. Rev. 177 (1985); Owen M. Fiss, Objectivity and Interpretation, 34 STAN. L. REv. 739 (1982).

Actually, to call Dworkin a "defender" of the concept of objectivity is a bit simplistic. Dworkin "defends" an oddly deflationary version of the concept. He claims, "[w]e use the language of objectivity, not to give our ordinary moral or interpretive claims a bizarre metaphysical base, but to repeat them, perhaps in a more precise way, to emphasize or qualify their content." DwoR- 
been the objectivity of specific legal judgments, judgments that apply blend legal concepts. In my view, appellate courts make only a small contribution to whatever objectivity any given blend legal judgment achieves. The inconclusiveness of the debate over objectivity in law owes, in my opinion, to the fact that both critics and defenders are looking for objectivity in the wrong place. Rather than examining the entire common law apparatus, scholars have generally checked only a small pocket, the appellate court opinion. It makes sense that some scholars then insist that law is objective, while others insist that it is not: appellate court opinions play a part, but only a part, in implementing the specifications of the conception of objectivity suitable for blend legal judgments.

This observation makes sense of Duncan Kennedy's ambivalence about objectivity in law. In his consideration of appellate court judging, Kennedy cannot resist the intuition that it is objective, yet he continually emphasizes that its objectivity is only apparent or "pseudo." 100 .Kennedy acknowledges that his intuition stems from the recognition that appellate judging is somewhat constrained, somewhat dialogical, and somewhat a matter of giving interpersonally available reasons. ${ }^{101}$ According to the blend conception, this means that appellate judgments meet, at least partially, some of the specifications for objectivity, thus making sense of Kennedy's feeling that appellate judgments are somewhat objective. Appellate judgments do not, however, meet all of the specifications for blend objectivity, nor do they, in isolation from the rest of the common law apparatus, fully contribute to satisfying the ones they do help to meet, perhaps explaining Kennedy's reluctance straightforwardly to count them objective.

Recognizing that appellate judicial decision plays a part - but only a part - in making blend legal judgments objective (to whatever degree they are objective) also helps make sense of why Stanley Fish's views on the objectivity of appellate judicial interpretation are simultaneously satisfying and dissatisfying. Fish continually insists that appellate judicial interpretation is objective because it is constrained constrained by the practice of judging itself. ${ }^{102}$ Again, as in the case of Kennedy, the blend conception justifies the significance Fish accords

KIN, EMPIRE, supra note 4, at 81 . While I share Dworkin's opinion that talk of objectivity need not be talk of metaphysics, I think that talk of objectivity amounts to more than repetition of claims made without such talk. Nonetheless, whatever his defiationism, Dworkin clearly thinks there is something to the concept of objectivity, and he argues strenuously that judicial decisionmaking is capable of objectivity.

100. Kennedy, supra note 5 , at 522 .

101. Id. at 520-22, 539 .

102. See, e.g., Fish, supra note 99, at 92-94, 109-10. 
to constraint: to the extent that appellate court blend judgments are constrained, they achieve a measure of objectivity. But the practice of judging, standing alone, is not really a very serious constraint, or so many have worried. ${ }^{103}$ If Fish were to broaden his scope, however, he would see that appellate court blend judgments are constrained by more than the "practice of judging." They answer to all of the constraints I discussed previously. 104

A pair of the intuitions that seems to drive some detractors of law's objectivity is that the law is "political," and that being "political" interferes with objectivity. ${ }^{105}$ The blend conception of objectivity turns these intuitions on their heads by incorporating a political dimension into the demands of objectivity. On the blend conception objectivity is - to a degree - a political matter, so being political does not preclude legal judgments from being objective. Two specifications for blend objectivity especially raise issues that would generally be regarded as "political." Specifying shared values, interests, and goals raises questions of which values, goals, and interests, if any, are shared; why certain ones are not; and how to bring any shared ones into being. Requiring regulation of power disparities raises questions about who is empowered relative to whom, and about when relative empowerment distorts dialogue, interferes with interpersonal availability of reasons, or renders convergence suspect. Checking to see whether and to what extent a blend legal judgment meets the specifications of shared values, interests, and goals and regulation of power disparities requires consideration of these questions. Inquiring into the objectivity of a blend legal judgment, then, inevitably calls for political inquiry. Failure to satisfy the specifications raises further political questions, such as what social, economic, and political arrangements would allow for the development of shared values, interests, and goals and redistribute power conducively for objectivity.

Overlap between politics and objectivity in blend legal judgment is inevitable, although this does not obviate sensible, workable distinc-

103. American legal realists, critical legal studies scholars, and liberal legal scholars have all been concerned that an individual judge's personal preferences, goals, and values can skew her appellate decisionmaking. See, e.g., DWORKIN, EMPIRE, supra note 4, at 228-38 (arguing that, when engaged in literary or judicial interpretation, one must be on guard against accepting purely "subjective" interpretations); Cohen, supra note 12, at 810-12 (arguing that courts write in terms that are useful only for expressing and inducing emotions and attitudes); Duncan Kennedy, Legal Formality, 2 J. LEGAL STUD. 351, 354-56, 385-87 (1973) (arguing that judges' "values, ends, goals, interests, [and] desires" necessarily enter into judicial decisionmaking, given logical impossibility of judge as (neutral) "rule applier").

104. See supra text accompanying notes 81-86.

105. James Boyle, The Politics of Reason: Critical Legal Theory and Local Social Thought, 133 U. PA. L. REv. 685, 687-91, 706-08 (1985); Peller, supra note 99, at 561-72, 606-17. 
tions between law and politics. Political matters bear on the objectivity of blend legal judgments, but they remain recognizably political. They become particularly important to blend legal judgments when the state of politics interferes with satisfying the specifications for blend objectivity. Failure or inability to meet these specifications provides good reason for political change: objectivity in legal judgment requires it. 106

Thus, the blend conception of objectivity answers to concerns raised by feminist and critical race scholars. ${ }^{107}$ It can provide critical leverage against legal judgments that have systematically oppressed or ignored the interests of those excluded from political and legal participation and power by revealing how this exclusion can undermine the objectivity of those judgments. Returning to the example of judgments of rape, ${ }^{108}$ here is a rough sketch of how the blend conception of objectivity provides resources for expressing feminist concern about such judgments: Insofar as men continue to enjoy greater economic, political, and social power than women, the values, interests, and goals that inform rape are unlikely to be widely or deeply shared, either between men and women or between members of the same sex. Moreover, these gendered power disparities also make it difficult for people to develop shared values, interests, and goals relevant to rape, by making it extremely difficult for people even to have fruitful conversation about the values, interests, and goals that do or should animate the concept, let alone come to agreement on these. Lack of shared values, interests, and goals and power disparity between men and women raise concern over the validity of judgments of rape at a more specific level, however. These problems interfere with the dialogical methodology conducted in the court system. That methodology is meant to contribute to blend objectivity by providing people from different perspectives similar opportunity to participate in each element of the process by which a blend legal judgment is reached. If, however, men still dominate the judiciary, the bar, and jury deliberations, this raises doubts as to whether the dialogical method can perform effectively in the process of making judgments of rape.

According to the blend conception, then, we have several reasons

106. This conclusion should be quite congenial to those who condemn law for being "political" and, so, not objective. They tend to seek progressive political change; blend objectivity supplies grounds for such change. Both Peller and Boyle advocate progressive political change. See Boyle, supra note 105, at 778-80; William N. Eskridge, Jr. \& Gary Peller, The New Public Law Movement: Moderation as a Postmodern Cultural Form, 89 MicH. L. REv. 707, 709, 748, $779-91$ (1991); Peller, supra note 99.

107. See supra text accompanying notes 1-5.

108. See supra text accompanying notes $94-95$. 
to doubt that judgments of rape enjoy a significant degree of objectivity. It is especially useful to be able to place feminist concerns about judgments of rape in the context of a concern for their objectivity because those who resist feminism may nonetheless value objectivity. Demonstrating what objectivity in legal judgment requires provides impetus for political change that might otherwise meet with resistance. Scholars arguing for such change should embrace the blend conception of objectivity.

Much previous argument over the objectivity of law has centered on whether there is a single right or one best answer in hard legal cases, or whether any legal case really has only a single answer. ${ }^{109}$ The blend conception obviates the need to debate these questions. When we turn to the question of whether, in any particular negligence action, there is one best, or only one possible, blend legal judgment, we see that the objectivity of the judgment does not depend on the answer. The blend conception requires that, for a judgment to be objective, it be constrained through dialogical method and empirical constraints, and supported by interpersonally available reasons. It is possible in some negligence actions that both an application of the concept to the defendant's activities and a refusal to apply the concept to his activities could be appropriately constrained and supported by interpersonally available reasons. In such actions, either a judgment of negligence or of nonnegligence would be objective, assuming the other specifications have been met. Which judgment is better will depend on other criteria for evaluating legal judgments. In many negligence actions, only a judgment of negligence or a judgment of nonnegligence will be appropriately constrained and supported by interpersonally available reasons. In these, only one or the other judgment will be objective. ${ }^{110}$ Note that, even in those cases in which

109. Dworkin, who writes about objectivity in various ways in various places, claims that appellate court decisions in hard cases attain a certain kind of objectivity when they ascertain the one best answer in such cases. See DwORKIN, EMPIRE, supra note 4, at 266-71. Tushnet sometimes argues that in all cases law is always radically indeterminate, and that therefore legal decision is never objective. See, e.g., Tushnet, supra note 99, at 804-27.

110. Again, those absorbed by whether there is a single right or one best answer in hard legal cases or whether any legal case really has only a single answer have generally thought about these questions in the context of appellate judicial decisions. My own view is that the system of layered constraints implemented by common law methodology does in fact constrain the decisions an appellate court may reach, thereby lending a degree of determinacy to appellate court judging. Karl Llewellyn, Duncan Kennedy, and Fred Schauer seem to hold something like this view. See Karl N. Llewellyn, The Common Law Tradition: Deciding Appeals 19-56 (1960); Frederick Schauer, Playing By the Rules 167-96 (1991); Kennedy, supra note 5, at 527-28. Some of the debate over indeterminacy in law has focused on rule skepticism, something that blend objectivity does not address. For the rule-skeptic argument, see Tushnet, supra note 99, at 804-24. For powerful refutations of the significance of rule skepticism for law, see SCHAUER, supra, at 191-96; Frank I. Michelman, Politics as Medicine: On Misdiagnosing Legal 
either a judgment of negligence or one of nonnegligence could be objective, there may be other grounds for preferring one judgment to the other, such as relative justness. ${ }^{111}$

I have tried to show how the blend conception serves to clarify ongoing debates within legal scholarship over the objectivity of legal judgments, allows for and motivates the politically oriented criticism that detractors of legal judgments want to make, and takes the sting out of what otherwise seems a thorny question regarding the objectivity of legal judgments. More generally, in the last Part of this essay, I have tried to show the power of the blend conception as a position in the scholarly arena, in addition to its power as a regulative ideal for practice.

\section{CONCLUSION}

Measured by the blend conception, different kinds of blend judgments vary in their potential for objectivity. I have illustrated this by comparing judgments of negligence and judgments of what is speech. The same point holds when we compare judgments of negligence with judgments of rudeness or judgments of humor. Without extensively reviewing the way the latter judgments fall short of the specifications, we can still quickly see their comparative lack of objectivity. For instance, few judgments of etiquette or humor are the topics of sustained dialogue. Few such judgments have interpersonal reasons regularly marshaled on their behalf. Likewise, convergence on such judgments tends to be more local and less durable than convergences related to judgments of negligence.

As these examples suggest, the lack of objectivity in judgments of humor and judgments of etiquette owes to the informal ways in which we usually make them. We do not have institutionalized systems for generating such judgments, designed to promote dialogue, the marshaling of interpersonal reasons, or convergence. In fact, to the extent we do institutionalize these judgments, such as through etiquette experts who publish their correspondences with readers, the resulting judgments come closer to achieving objectivity. The correspondence between Miss Manners and her readers creates a dialogue, in which Miss Manners's knowledge and expertise regarding the practice of etiquette constrain her readers while at the same time their real-world experiences constrain her interpretations of that practice. The process

Scholarship, 90 YALE L.J. 1224, 1226-28 (1981); Lawrence B. Solum, On the Indeterminacy Crisis: Critiquing Critical Dogma, 54 U. CHI. L. Rev. 462 (1987).

111. For a discussion of possible grounds, other than objectivity, for accepting blend judgments, see infra text accompanying notes 112-15. 
instantiates, to some degree, dialogical constraint. By and large, though, when it comes to most judgments of etiquette, no such process occurs. Moreover, this rarely matters. This view may surprise, coming from someone who has been defending the idea of objectivity. But now that we have a better grip on what objectivity in blend judgment involves, we can see that objectivity may well be less important for some kinds of blend judgments than others.

Objectivity does matter to blend legal judgments. Recall the relationship between objectivity and interpersonal validity. It is very important for legal judgments to have interpersonal validity. Sanctions go only so far in producing obedience to the law; in any event, purely fear-driven obedience is not what we seek. We want the law to be interpersonally valid in its own right. We do not want a government that must coerce and pressure citizens into obeying the law.

Closely related to the issue of law's interpersonal validity is the issue of law's legitimacy. ${ }^{112}$ Take the following as a basic working elucidation: a judgment is legitimate to the extent that it is based on appropriate grounds. ${ }^{113}$ Legitimacy licenses the imposition of the judgment on dissidents; that is, if a judgment is legitimate it is appropriate to penalize those who dissent from it. ${ }^{114}$

In principle, it is possible that objectivity is sufficient to establish legitimacy: that the only ground necessary to license imposition of a judgment on dissidents is that the judgment be objective. In the case of legal judgments, however, objectivity is not sufficient. Their legitimacy requires at least one other feature: justness. A blend legal judgment that fully meets the specifications for objectivity but is nevertheless thoroughly unjust would be relatively illegitimate, although not completely so, in comparison to a blend legal judgment that is both objective and just. More strikingly, the reverse of this point also holds: a blend legal judgment that is just, but wholly lacking in objectivity, is relatively illegitimate, although not completely so, in comparison to a blend legal judgment that is both just and objective. To understand the force of this point, imagine a corrupt jurisdiction in

112. PhILIP SOPER, A THEORY OF LAW 4-12, 38-56, 95-100 (1984) (discussing the relationship between legitimacy and obligation to obey the law). Legitimacy is a concept that merits at least as much attention as objectivity, but that is another project.

113. Even this very thin working elucidation is sure to provoke negative reaction - that is why legitimacy deserves as much attention as objectivity. One question immediately surfaces: is legitimacy a matter of appropriate grounds or a matter of perceived appropriate grounds? This is a more particular version of a general question about legitimacy: whether it is a matter of acceptance or a matter of what ought to be accepted. My own preference, undefended here, is for the latter formulation. That is, I would distinguish between genuine legitimacy and felt legitimacy. In the text, I refer to genuine legitimacy.

114. The appropriate degree of severity of the penalty is a further, separate question. 
which a single judge makes judgments of negligence solely on the basis of how she is bribed. By coincidence, some of these judgments are just, on whatever theory of substantive justice you like. I do not think we would take these judgments to provide the same measure of license to force the losing party to go along as we would if the judgments were also objective - although arguably they provide a greater measure of license than those of the judge's judgments that are not even just.

So objectivity grounds a blend legal judgment's legitimacy. As for other types of blend judgments, objectivity may play little role in supporting their legitimacy or, more radically, legitimacy may matter little to them. Both interpersonal authority and legitimacy seem quite beside the point for judgments of humor and less crucial for judgments of etiquette than judgments of law, no doubt due to the respective places of humor, etiquette, and law in our culture. If we relied on etiquette (or humor?) to perform the complex, extensive regulatory functions we now assign to law, we would want judgments of etiquette to be interpersonally authoritative and expect them to be legitimate. But our culture, unlike some others, turns to law. So we need our blend legal judgments to be objective far more than we need objectivity from our blend judgments of etiquette. ${ }^{115}$

It is good that we do not always need objectivity from all of our blend judgments. Objectivity is costly. In financial terms alone, it is quite expensive. The blend conception of objectivity need not be implemented in the form of common law methodology, but any implementation is likely to be financially draining. Creating systematic opportunities and mechanisms for constraint, dialogue, convergence, the formation of interpersonal reasons, and so on requires monetary might. Consider the financial expense of the common law system do not forget the expenses of educating attorneys, financing law schools, and collecting and publishing judicial opinions. Money spent on implementing blend objectivity is money not spent elsewhere. The same is true of human resources not best understood financially. Something like the common law system takes a lot of talented manpower. Putting this talent and hard work into that system exacts an opportunity cost - fewer human resources for other endeavors.

The method for achieving objectivity upon which I have focused is

115. For us, the other domain upon which we rely seriously to regulate interpersonal relations and activities is ethics. I have not used ethical blend judgments as a comparison class to blend legal judgments because they are, in some ways, too similar. To the extent that one of their similarities consists in similarity of regulatory function, we need objectivity in ethical judgments as much as we need objectivity in legal judgments. But, as I discuss in the text below, creating objectivity is costly, in a number of respects. Before we insist upon objectivity in ethical judgment, we need to decide whether we can - or want to - afford it at its price. 
the common law system of adjudication, in part because we aspire to objectivity in our common law judgments. Denunciations of law's objectivity sting. This evidences our desire and need for a fairly high degree of objectivity in blend legal judgments. If objectivity did not matter in the legal context, we would simply shrug off the critiques. As it is, we can recast the critiques as illuminations of when, where, and how legal judgments fall short of the regulative ideal provided by the blend conception of objectivity, even as we deny the persuasiveness of the critiques as attacks on the ideal itself. Moreover, we can insist that our legal judgments more closely satisfy the ideal. 